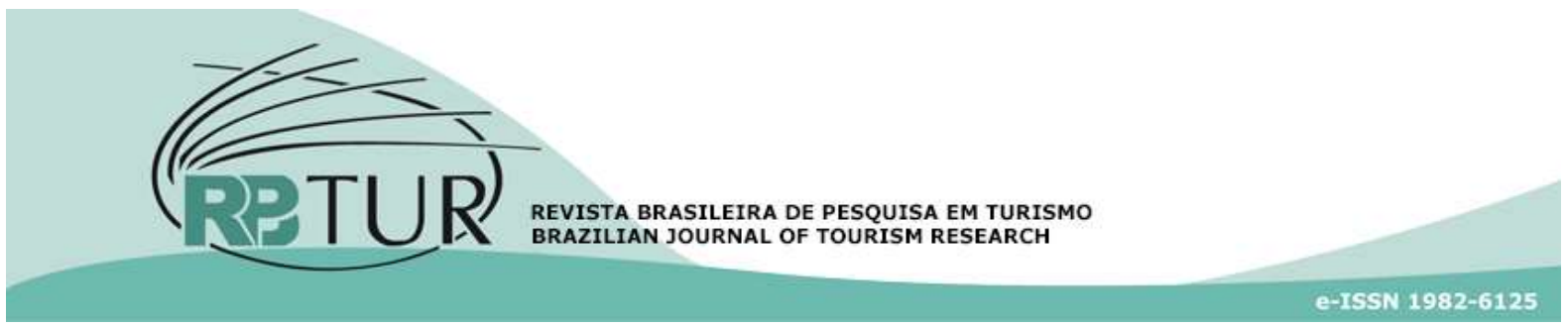

Artigo

DOI: http://dx.doi.org/10.7784/rbtur.v12i3.1417

\title{
Cultura, sustentabilidade e a imagem de destinos turísticos: um estudo comparativo nas sub-regiões do Brasil
}

\author{
Culture, sustainability and tourism destination image: a comparative \\ study on the sub-regions of Brazil
}

\section{Cultura, sustenabilidad y la imagen de destinos turísticos: un estudio comparativo en las diferentes subregiones de Brasil}

\section{Adrielly Souza Silva ${ }^{1}$ Anderson Gomes de Souza ${ }^{2}$}

Resumo: O emprego da 'sustentabilidade' enquanto fator de diferenciação mercadológica tem sido recorrente entre os destinos turísticos. Entretanto, a imagem destas localidades não está alheia à influência de fatores externos, como a cultura. Em países com dimensões territoriais amplas, como o Brasil, este fenômeno tende a ser ainda mais evidente. Isto porque, em termos culturais, não existe somente um, mas cinco diferentes 'Brasis' (Ribeiro, 1995). Assim, esta pesquisa se propõe a analisar como a imagem da sustentabilidade de destinos turísticos pode ser influenciada pelas características culturais das sub-regiões de origem dos consumidores brasileiros. O caráter inovador do estudo decorre da adoção de uma abordagem idiográfica das dimensões culturais de Hofstede (1980). Foram realizados cinco grupos focais com indivíduos de nacionalidade brasileira, nas diferentes regiões culturais do país, cujos dados foram analisados por meio da técnica da análise de conteúdo. Os resultados demonstraram que, das cinco sub-regiões analisadas, o 'Brasil Sulinas' apresentou maior discrepância

${ }^{1}$ Universidade Federal de Pernambuco (UFPE), Recife, PE, Brasil. A autora participou de todo o processo de elaboração do estudo. Sua contribuição deu início com o refinamento do tópico de pesquisa, prosseguindo com a elaboração da revisão de literatura. Tendo bem estabelecido o modelo teórico, sob a orientação plena do professor, delimitou os procedimentos metodológicos, esteve à frente da coleta dos dados nas cinco regiões do Brasil, analisou os dados, apresentou e discutiu os resultados e redigiu as conclusões finais. Após a análise de profissionais e acadêmicos qualificados na área, bem como a orientação do professor, refinou o texto em termos de conteúdo e de estrutura, até que estivesse pronto o documento final.

2 Universidade Federal de Pernambuco (UFPE), Recife, PE, Brasil. Concepção e desenho inicial da pesquisa. Revisão da literatura. Delimitação do domínio dos construtos. Orientação para o desenvolvimento de cada uma das etapas. Definição de métodos e instrumentos para a coleta de dados do estudo. Auxílio na coleta, tratamento e análise dos dados. Revisão do manuscrito final, bem como nas versões em português, inglês e espanhol submetidas à Revista.

Artigo recebido em: 07/02/2018. Artigo aceito em: 31/08/2018.

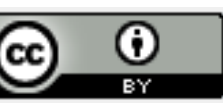


quanto à imagem da sustentabilidade de destinos turísticos. Fato este atribuído a uma maior propensão a valores correspondentes a índices elevados de masculinidade e baixa aversão a incertezas. Já os consumidores das demais sub-regiões tenderam a demonstrar padrões de pensamento semelhantes entre si, mas contrários ao 'Brasil Sulinas'.

Palavras-chave: Imagem. Destinos turísticos. Dimensões culturais. Regiões culturais do Brasil. Sustentabilidade.

Abstract: The use of 'sustainability' as a factor of market differentiation has been recurrent among tourism destinations. However, the image of these settings is not free of influence of external factors, such as culture. In countries with large territorial dimensions, such as Brazil, this phenomenon tends to be even more evident. This is because, in cultural terms, there is not only one, but five different 'Brasils' (Ribeiro, 1995). Thus, this study aims to analyze how the image of the sustainability of tourism destinations can be influenced by the cultural characteristics of the Brazilian consumers' sub-regions of origin. The innovative character of the study stems from the adoption of an idiographic approach to the cultural dimensions of Hofstede (1980). Five focus groups were conducted among Brazilian nationals, within the different cultural regions of the country, and the data were analyzed through content analysis technique. The results showed that, from the five subregions analyzed, the 'Brasil Sulinas' presented a greater discrepancy regarding the image of the sustainability of tourism destinations. This fact was related to a higher propensity to values corresponding to high levels of masculinity and low aversion to uncertainties. On the other hand, the consumers from the other subregions tended to show similar patterns of thought among themselves, yet contrary to the 'Brazil Sulinas'.

Keywords: Image. Tourism attractions. Cultural dimensions. Cultural regions of Brazil. Sustainability.

Resumen: El empleo de la 'sostenibilidad' como factor de diferenciación mercadológica ha sido recurrente entre los destinos turísticos. Sin embargo, la imagen de estas localidades no está ajena a la influencia de factores externos, como la cultura. En países con dimensiones territoriales amplias, como Brasil, este fenómeno tiende a ser aún más evidente. Esto debido a que, en términos culturales, no existe solamente uno, sino cinco diferentes 'Brasiles' (Ribeiro, 1995). Así, esta investigación propone analizar cómo la imagen de la sustentabilidad de destinos turísticos puede ser influenciada por las características culturales de las subregiones de donde provienen los consumidores brasileños. El carácter innovador del estudio se deriva de la adopción de un enfoque idiográfico de las dimensiones culturales de Hofstede (1980). Se realizaron cinco grupos focales con individuos de nacionalidad brasileña, en las diferentes regiones culturales del país, cuyos datos fueron analizados por medio de la técnica del análisis de contenido. Los resultados demostraron que, de las cinco subregiones analizadas, el 'Brasil Sulinas' presentó mayor discrepancia en cuanto a la imagen de la sostenibilidad de destinos turísticos. Este hecho es atribuido a una mayor propensión a valores correspondientes a índices elevados de masculinidad y baja aversión a incertidumbres. Los consumidores de las demás subregiones tendieron a demostrar patrones de pensamiento semejantes entre sí, pero contrarios al 'Brasil Sulinas'.

Palabras clave: Imagen. Destinos turísticos. Dimensiones culturales. Regiones culturales de Brasil. Sostenibilidad.

\section{INTRODUÇÃO}

Compreender a cultura é um esforço que tem despertado o interesse de estudiosos no campo das ciências humanas e sociais já há algum tempo (Sahlins, 2013). Ainda na década de 1980, em seu estudo intitulado Culture's Consequences: International Differences in WorkRelatedValues, Hofstede (1980) sugeriu que a cultura fosse tratada como uma 'programação coletiva' da mente. Para tanto, entendia-se que os indivíduos, representados pela coletividade de um grupo social, comportavam-se de acordo com o que ele denominou como 'software' da mente. Ainda na visão do autor, os membros de um determinado grupo social eram considerados detentores de tal programação em função do conjunto de regras e hábitos comportamentais que lhes foram socialmente transferidos. 
Com base nesse pressuposto, alguns estudos passaram a buscar evidências que direcionassem a conclusões a respeito do efeito da cultura sobre o comportamento de determinados grupos sociais. Este movimento foi responsável pelo surgimento e, consequentemente, pelo emprego de um conjunto de dimensões culturais, capazes de acessar com maior precisão o fenômeno (Hall \& Hall, 1990; Hofstede, 2001; Houseet. al., 2004). O pioneiro foi, sem dúvidas, Hofstede (1980), ao desenvolver pesquisa com funcionários da IBM em mais de setenta países ao redor do mundo. O resultado disso foi a proposição das cinco dimensões de cultura (Masculinidade, Distanciamento de poder, Aversão à incerteza, Individualismo e Orientação ao longo prazo) que, nos anos seguintes, passaram a ser aplicadas a diferentes áreas do conhecimento.

Embora se reconheça o valor dessas dimensões, deve-se destacar que sua aplicação estava restrita à compreensão de comportamentos sociais em nível nacional (Brewer\&Venaik, 2012). Diante disso, autores como Ribeiro (1995) seguiram por outro caminho, propondo para o estudo da cultura a noção de subculturas, capazes de orientar as ações de diferentes grupos dentro de uma mesma nação. Ribeiro (1995) considerava, por exemplo, que existia não um, mas cinco diferentes 'Brasis'. Isto significa dizer que, em se tratando de um país com dimensões territoriais extensas, como o Brasil, é inevitável, e até certo ponto esperado, que haja alguma variação no comportamento de certos grupos regionais (Maia, 2015).

Entretanto, há de se destacar que, ao longo das últimas décadas, a abordagem comparativa nacional, pioneiramente proposta por Hofstede (1980), ganhou grande espaço no meio acadêmico. Estudos como os de Valsiner (2007), Schein (2010) e Tabellini (2010), por exemplo, exploram a relação da cultura com os elementos que envolvem a psicologia humana, o comportamento organizacional e o nível de desenvolvimento econômico de uma nação. Já no campo de estudos em marketing e comportamento do consumidor, Mooij (2014) buscou inserir o assunto nas discussões a respeito de como os indivíduos de certas sociedades agem e reagem no momento de escolha e decisão de compra. Conforme argumentam Souza et. al. (2014), tal perspectiva foi precedida pelos estudos de Douglas (1979) e McCracken (1986), cujo principal objetivo era analisar a complexidade do comportamento de consumo, tendo como base parâmetros socioculturais.

Ainda no campo do consumo, Jaworski \& Macinnis (1986) focaram na compreensão do impacto da cultura sobre o processo de formação de imagens. Para eles, este era um processo que dizia respeito à interpretação do consumidor em relação a determinados produtos/marcas. Por se tratar de algo tão subjetivo e, ao mesmo tempo, indissociável do aspecto cultural, Roth (1995) propôs que o fenômeno fosse abordado sob o prisma dos valores que definem as diferentes sociedades. Isto não é uma exceção do ponto de vista turístico, haja vista que autores como Warren \& Dinnie (2018) destacam que a imagem do lugar, elemento imprescindível para o estabelecimento eficaz da marca de um destino (Kavaratzis, 2005), pode ser influenciada por componentes culturais. Diante disso, Souza et. al. (2014) sugeriram 
que, também no campo do turismo, a imagem do consumidor (turista potencial) em relação a um destino turístico fosse analisada sob a mesma ótica. Isto porque, em se tratando da imagem de destinos, os elementos que compõem certas culturas podem afetar diretamente na interpretação do consumidor quanto ao 'produto turístico', principalmente por esses serem oriundos de regiões geográficas distintas.

Para Buhalis (2000), Hassan (2000) e, mais recentemente, Cucculelli\&Goffi (2016), uma das estratégias mais utilizadas pelos destinos turísticos para atrair a atenção dos consumidores é o argumento da 'sustentabilidade'. Não raro, gestores de destinos e profissionais de marketing turísticobuscam construir identidades (Kotler \&Gertner, 2002; Aaker, 2004) que possam ser facilmente associadas ao caráter sustentável de uma localidade (Zouganeliet.al., 2012; Andrade et. al., 2013). Anos atrás, esta até poderia ser uma estratégia válida, dado o grau de competitividade entre os destinos, e a necessidade urgente de diferenciação mercadológica destes. No entanto, conforme propõem Souza et. al. (2014), não se pode falar em estratégia de distinção de mercado quando, em verdade, grande parte dos players, empresas e organizações que participam de uma determinada atividade (Cambridge Dictionary Online, 2018), recorrem aos mesmos argumentos.

Portanto, considera-se, neste estudo, que os destinos turísticos precisam adotar estratégias de diferenciação cada vez mais direcionadas às especificidades do seu públicoalvo. Isto porque, segundo Kavaratzis (2005), a eficiência da marca de um local depende da percepção dos consumidores, isto é, da sua imagem. Ao mesmo tempo, sabe-se que, no turismo, o processo de interpretação do consumidor em relação à um destino turísticonão está alheio a influências culturais, sendo a cultura uma das dimensões que formam a marca-de-lugar (Warren \&Dinnie, 2018; Mariutti \& Medeiros, 2018).

Com base nisso, esta pesquisa foi desenvolvida com o objetivo de compreender como a imagem dasustentabilidade de destinos turísticos pode ser afetada pelas características culturais dos consumidores brasileiros residentes (e locais) de cinco sub-regiões culturais da nação (Ribeiro, 1996). Diante de um paradigma interpretativista, a investigação adotou métodos qualitativos, coerentes com a proposição de um estudo idiográfico (Fellows, 2013). Enquanto instrumento de coleta, foram realizados cinco grupos focais, em Recife, Belém, Brasília, Porto Alegre e São Paulo, cidades-polo que representaram as sub-regiões do país. Os dados obtidos foram categorizados e analisados por meio de técnicas da análise de conteúdo (Bardin, 1977).

Destarte, pretende-se não somente expandir os estudos em turismo, mas também preencher uma lacuna teórica de investigações que estejam direcionadas às influências culturais do Brasil na imagem da marcade-lugar.No intuito de facilitar o entendimento do leitor acerca do assunto, os tópicos a seguir abordam os principais construtos do modelo teórico definido como base para esta investigação.

\section{REFERENCIAL TEÓRICO}

\subsection{Conceito de cultura e as dimensões cul- turais de Hofstede}

Já há alguns anos, ainda na década de 
1950, autores como Kluckhohn (1951), Kroeber \& Parsons (1958) buscavam compreender de forma mais aprofundada os principais elementos que caracterizavam o campo de domínio da cultura. Para Kluckhohn (1951), este construto consistia em maneiras padronizadas de pensar, sentir e reagir, podendo ser adquiridas e transmitidas essencialmente por meio de símbolos. Kroeber \& Parsons (1958), por sua vez, foram um pouco mais além, abrangendo o nível de análise ao propor que a cultura estivesse relacionada a todo e qualquer conteúdo que pudesse ser transmitido e criado no âmbito social, sendo responsável por orientar e moldar o comportamento humano.

Mais à frente, outros autores também trabalharam na construção de um entendimento para este construto. Hofstede (1980), por exemplo, compreendia a cultura como uma programação coletiva da mente, interpretação conceitual tomada como base nesta investigação. De acordo com o autor, os indivíduos de um grupo social comportavam-se de acordo com a sua programação (ou 'software') mental. Para chegar a esta conclusão, o autor teve apoio no campo empírico, de forma complementar ao teórico, com a realização de pesquisa em mais de 70 países em meio aos funcionários da International Business Machines (IBM). Foi assim, portanto, que o autor chegou à conclusão de que o comportamento humano poderia ser transmitido entre os membros dos grupos sociais ao longo dos anos, além de ser, em certo modo, previsível.

Foi justamente com base nesta previsibilidade que Hofstede (1980) propôs um conjunto de dimensões culturais, a partir das quais as culturas puderam ser analisadas e compreendidas em um nível cross-cultural de estudo. Neste caso, a unidade de análise adotada foi a nação, uma vez que foi percebida certa homogeneidade de comportamentos entre os grupos nacionais (Brewer \& Venaik, 2012; Fellows, 2013). As dimensões culturais foram denominadas e caracterizadas por Hofstede (1980) da seguinte forma:

(1) Distanciamento de poder: Grupos sociais que apresentam uma elevada propensão ao distanciamento de poder geralmente aceitam e respeitam ordens hierárquicas (Souza et. al., 2014). Por outro lado, grupos sociais com baixa propensão ao distanciamento de poder se esforçam para equalizar a distribuição de autoridades em sua sociedade.

(2) Aversão à incerteza: Elevado índice de aversão à incerteza representa grupos sociais com baixa tolerância para contextos ambíguos, imprevisíveis e arriscados (Money et. al., 2003). Logo, estas sociedades buscam por garantias que assegurem a sua estabilidade, sendo comum a existência de um regulamento mais influente, baseado em leis e normas, além de maior intervenção governamental. Por outro lado, baixos índices de aversão à incerteza indicam sociedades que se expõem mais aos riscos e são mais receptivas ao lidar com situações incertas.

(3) Individualismo: Os laços que unem os indivíduos em sociedades individualistas tendem a ser menos rígidos, priorizando as realizações individuais. Nestas sociedades, cada um deve as- 
sumir as consequências de seus atos e os interesses pessoais são prioridade. Por outro lado, sociedades mais coletivistas tendem a priorizar o coletivo e o bem-comum (Souza et. al., 2014).

(4) Masculinidade: Propõe que grupos sociais cujos valores se apresentam predominantemente masculinos são orientados para a realização, heroísmo, assertividade, recompensas materiais e, em geral, tais sociedades são mais competitivas. Por outro lado, a feminilidade representa na sociedade um predomínio de valores como cooperação, modéstia e qualidade de vida (Hofstede, 2001).

(5) Orientação ao longo prazo: Uma sociedade com orientação ao longo prazo, denominada por Hofstede (2001) como pragmática, destaca-se pela sua propensão para ações com resultados futuros, tais como o investimento em poupança e os esforços para a modernização da educação. Por outro lado, sociedades com orientação ao curto prazo, também chamadas de normativas, prezam pela manutenção das tradições e normas ao lidarem com situações de mudanças sociais.

Pode-se dizer que tais dimensões culturais foram baseadas em uma abordagem de investigação cultural Etic, também conhecida como nomotética (Hofstede, 2001). Este tipo de abordagem volta-se para uma visão externa e emprega uma perspectiva de caráter positivista. Entretanto, a abordagem Etic não é a única forma utilizada pelos estudiosos para investigar os fatos culturais, podendo também ser empregada a abordagem Emic (idiográfica) (Fang, 2003; Fellows, 2013).

Nas pesquisas intituladas Emic, como a proposta por este estudo, as análises são direcionadas para dentro de um mesmo grupo social. Portanto, tendem a assumir um caráter construtivista (Fellows, 2013). Estudos que analisam os aspectos culturais a partir de uma abordagem Emic, como o de Conner \& Tennen (2009), assumem, em geral, que estes somente poderão ser investigados se analisados a partir da própria perspectiva cultural do grupo. No turismo, especificamente, pesquisas idiográficas, tal como propõe essa investigação, ainda são escassas.

\subsection{Regiões brasileiras: uma abordagem idi- ográfica de cultura}

A investigação de Ribeiro (1995) representa um dos exemplos de pesquisas que assumiram a qualidade idiográfica. Ao investigar em profundidade os elementos culturais que orientam a sociedade brasileira, o autor se propôs a estudar a heterogeneidade de um único grupo social a partir da sua própria perspectiva cultural, que neste caso era representada pela nação brasileira. De tal modo, algumas das características que Fellows (2013) evidenciou como sendo parte das investigações idiográficas estão fortemente presentes no estudo de Ribeiro (1995).

Segundo Giarola (2012), Ribeiro (1995) analisou o cenário heterogêneo do povo brasileiro tomando como base o processo de formação e os fatos históricos desta nação. Assim como ele, Holanda (1936), em 'Raízes do Brasil', também havia investigado 
a característica múltipla da comunidade nacional brasileira. Ambos os autores se debruçaram sobre os fatos históricos na tentativa de explicar a amplitude de características culturais que estariam presentes em um único grupo nacional, com respeito às diferentes linhas de pesquisa que os autores assumiam.

Para Ribeiro (1995), existem no território brasileiro cinco regiões culturais que, apesar de pertencerem à mesma matriz, são formadas por diferentes características culturais. Uma década após, Ortiz (2005) foi ainda mais além ao afirmar que, no território brasileiro, não existe apenas uma identidade cultural, mas sim múltiplas, todas carregadas por seus próprios eventos históricos. Mais recentemente, Maia (2015) complementou à compreensão dos autores supramencionados ao afirmar que, no âmbito de uma dimensão nacional, é natural que existam diferentes identidades culturais.

A cada uma das sub-regiões culturais brasileiras foram atribuídas as seguintes denominações: (1) Brasil Crioulo, (2) Brasil Caboclo, (3) Brasil Sertanejo, (4) Brasil Caipira e (5) Brasil Sulinas. Ao estudar e entender as diferenças culturais dos sertanejos nordestinos, dos caboclos da Amazônia, dos crioulos do litoral, dos caipiras do Sudeste e do centro do país e dos gaúchos das campanhas sulinas, Ribeiro (1995) destacou a pluralidade cultural da sociedade brasileira (Miglievich, 2011). Num país com amplas dimensões continentais e originário de um processo de formação tão peculiar, como é o caso do Brasil, é possível que exista uma extensa heterogeneidade de comportamentos moldados por influências culturais.

\subsection{A influência da cultura na imagem}

Os fatores culturais conduzem a vida humana podem ser responsáveis por orientar muitos dos aspectos que estão relacionados ao comportamento coletivo. Dentre estes, pode-se destacar a influência que os elementos culturais exercem sobre o comportamento de consumo no geral (Mooij, 2014), o que inclui a imagem do produto percebida pelos consumidores (Warren \& Dinnie, 2018). Imagem esta que, nesta investigação, é conceitualmente compreendida como um processo de interpretação do consumidor em relação aos elementos tangíveis e não tangíveis de um produto, cuja percepção resulta em 'fotografias mentais' (Stern, Zinkhan \& Jaju, 2001).

Já há algum tempo, estudiosos que investigaram o comportamento do consumidor afirmaram que esta imagem é formada pelas variáveis mais subjetivas dos indivíduos, sobre as quais estão os aspectos culturais. Park, Jaworski e Macinnis (1986), por exemplo, chamavam a atenção para o fato de a imagem ser compreendida como um processo interpretativo no qual a cultura se faz fortemente presente. Ainda na década de 90, Roth (1995) também destacava a necessidade de considerar a cultura ao afirmar que os aspectos globais exercem influência no comportamento do consumo, fato que, mais à frente, foi reafirmado e defendido por Mooij (2014).

Para Roth (1995), esta compreensão deveria se estender as mais diversas áreas de conhecimento nas quais esse campo de pesquisa possa ter influência, dentre as quais está o turismo. Neste setor, especificamente, autores como Bonn, Joseph \& Dai (2005) e Kastenholz (2010) evidenciaram que o 
background cultural dos consumidores turísticos poderia influenciar seu processo de interpretação em relação a um destino turístico, exercendo influência direta na imagem destes. Esta, por sua vez, é especialmente importante para a eficácia da marca-de-lugar (Kavaratzis, 2005) e, não raro, costuma ser influenciada por componentes culturais (Warren \&Dinnie, 2018).

\subsection{A imagem dos destinos turísticos e a sus- tentabilidade}

Frequentemente, a sustentabilidade, compreendida nesta investigação como um fenômeno de preservação, conservação e proteção dos pilares social, econômico e ambiental (Turner, Pearce \&Bateman, 1994), tem sido um dos principais argumentos utilizados pelas localidades na formulação das suas identidades (Dinnie, 2015). Em função disso, ela tem sido assimilada pelos consumidores como parte da imagem dos destinos (Zouganeli et.al., 2012). Neste cenário, segundo Souza et. al. (2014), é cada vez mais comum a utilização de elementos que remetem aos três pilares da sustentabilidade (ambiental, social e econômico) em campanhas promocionais que visam à atração de novos consumidores turísticos.

Entretanto, autores como Schultz et. al. (2005) e Roy \& Goll (2014) sugeriram que diferentes sociedades poderiam assumir atitudes distintas quanto à sustentabilidade. Consequentemente, os estudiosos admitique pudesse haver formas particulares de comportamento sustentável, baseadas em expectativas culturais que poderiam afetar a imagem dos consumidores (Husted, 2005). Isto, de acordo com Souza et. al. (2014), tam- bém poderia acontecer na atividade turística.

Conforme arcabouço teórico apresentado, a imagem dos produtos pode ser influenciada pelos elementos culturais dos consumidores (Mooij, 2014), o que não é diferente em se tratando da imagem de destinos turísticos (Kastenholz, 2010; Warren \& Dinner, 2018). Isto, segundo Ribeiro (1995), pode ser ainda mais peculiar no Brasil, haja vista que nesta nação há variações culturais de uma região para outra. Paralelo a isso, a imagem de destinos turísticos tem sido constantemente associada à sustentabilidade (Souza et. al., 2014), haja vista a inserção deste elemento na marca dos locais (Kavaratzis, 2005). A partir de uma congruência entre tais teorias, é possível que a imagem da sustentabilidade de destinos turísticos possa ser influenciada pelas características culturais das sub-regiões de origem dos consumidores brasileiros.

\section{METODOLOGIA}

\subsection{Pressupostos da pesquisa}

Esta pesquisa qualitativa, de caráter descritivo, foi desenvolvida a partir de um corte transversal de estudo. Para sua implementação, fez-se necessária a identificação de traços culturais na sociedade brasileira, previamente dividida em cinco sub-regiões. Posteriormente, os padrões observados foram associados à imagem dos consumidores em relação a destinos turísticos, conforme já debatido na introdução e na revisão da literatura.

A abordagem adotada para este estudo foi a cross-cultural idiográfica (Hofstede, 2001; Harkness, Vijver \& Mohler, 2003), uma vez que houve a intenção de comparar 
diferentes culturas dentro de um mesmo grupo nacional. Apesar de grande parte dos estudos cross-culturais assumirem o caráter nomotético, por focarem na análise comparativa entre países, o método empregado nesta investigação seguiu uma perspectiva distinta, visto que o foco se centrou na análise de subculturas de uma mesma nação (Fang, 2003; Fellows, 2013).

O Brasil foi escolhido como objeto de estudo devido à sua vasta extensão territorial e à multiplicidade de culturas que, historicamente, deram origem à nação. Tais características, segundo Ribeiro (1995), resultaram no surgimento de diferentes regiões culturais. Conforme sugere o próprio autor, existe não um, mas cinco diferentes 'Brasis'. Diante disso, optou-se por compreender, de forma mais profunda, como as especificidades de cada uma dessas sub-regiões poderia afetar o comportamento de consumo dos brasileiros.

Nesta investigação, foi elaborada uma proposta de mapeamento destas sub-regiões (Figura 1), assim como também foram definidas algumas cidades-polo (Belém, Recife, Goiânia, São Paulo e Porto Alegre). Isto foi feito com base teórica, atentando a determinados trechos da obra 'O Povo Brasileiro' em que o próprio Ribeiro (1995) relata áreas de abrangências geográficas destes 'Brasis', assim como também elucida o papel de algumas cidades na formação destas sub-regiões.

Figura 1 - Proposta de mapeamento dos 'Brasis'

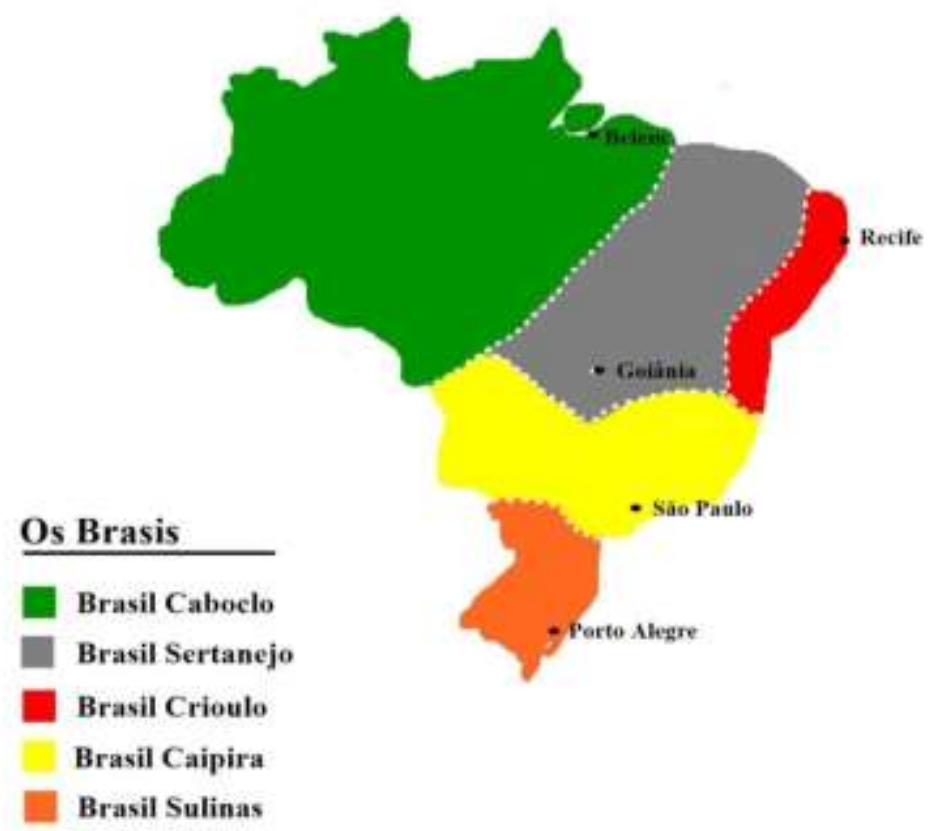

Fonte: Proposição dos autores (2017)

É importante ressaltar que, embora separações espaciais foram pontilhadas. Asesta delimitação geográfica tenha sido pro- sim, houve a preocupação de não fazer o que posta pelos autores, este estudo não preten- Laraia (1986) entendia como 'determinismo de enfatizar uma exatidão entre as fronteiras geográfico', enfatizando que não há divisões geográficas dos 'Brasis', motivo pelo qual as enraizadas de características culturais entre 
os 'Brasis'. Respeita-se o fato de que diferenças e particularidades possam existir, independente das ocupações geográficas. No entanto, para esta investigação de abordagem cross-cultural, a proposição de um mapeamento foi um recurso considerado importante e necessário para a separação dos 'Brasis' em unidades de análise, possíveis de serem comparadas.

Para tanto, definiu-se a imagem da sustentabilidade de destinos turísticos como elemento central de análise do estudo, por se tratar desta uma das dimensões de marcade-lugar, conforme sugere Dinnie (2015).Em geral, para se chegar a conclusões para problemáticas de pesquisa como esta, o mais indicado é a adoção da abordagem idiográfica, também conhecida como 'Emic' (Fellows, 2013). Para Mooij (2010), ao contrário dos estudos de caráter 'Etic', ou nomotéticos, as pesquisas idiográficas se limitam à busca pelo entendimento das influências da cultura sobre o comportamento social de um grupo específico que, neste caso, pode ser representado por um país.

\subsection{Procedimentos de coleta de dados}

O corpus desta investigação foi composto por indivíduos de nacionalidade brasileira.Além disso, houve uma delimitação na faixa etária, uma vez que os indivíduos selecionados possuíam idade acima de 18 anos, maioridade legal no Brasil. Todos os participantes eram locais (e residentes) de uma das cinco regiões culturais propostas por Ribeiro (1995), novamente mantendo o corpus em consonância ao que foi proposto pela investigação.

A coleta dos dados primários da fase empírica desta investigação se deu por meio da realização de diferentes grupos focais. No total, foram conduzidos cinco grupos de discussão, ao longo de cinco meses, sendo um em cada sub-região cultural brasileira proposta por Ribeiro (1996), nas 'cidades-polo' representantes dos diferentes 'Brasis' (Figura $1)$.

A decisão de limitar o número de cidades a cinco surgiu das restrições financeiras e de tempo para a operacionalização do estudo, dadas as dimensões geográficas do Brasil. Destarte, com exceção do grupo focal realizado em Recife, todos os demais foram conduzidos por meio de vídeo-chamadas (Poynter, 2010; Stewart \& Shamdasani, 2014).Em se tratando da coleta de dados qualitativos em meio a grupos geograficamente separados, o uso de recursos tecnológicos se torna uma alternativa viável para a operacionalização dos estudos (Stewart \& Williams, 2005). Portanto, a adoção deste tipo de recurso foi fundamental no sentido de possibilitar a obtenção de dados desta pesquisa, uma vez que as cidades-polo que representaram as sub-regiões estão geograficamente distantes.

Participaram desta etapa estudantes de cursos relacionados ao campo da Hospitalidade (Turismo, Hotelaria e Gastronomia), partindo do pressuposto de que estes indivíduos, representados por sua escolaridade, já possuíam determinado grau de familiaridade com a atividade turística. Na ocasião, contouse com a colaboração de professores/pesquisadores de cinco Instituições de Ensino Superior no Brasil, que se disponibilizaram para operacionalizar os grupos focais, a saber: Universidade Federal de Pernambuco - UFPE, Universidade Federal do Pará - UFPA, Univer- 
sidade de Brasília - UnB, Centro Universitário IPA, de Porto Alegre, e a Universidade Anhembi Morumbi - UAM. O Quadro 1, a se- guir, detalha a quantidade de participantes e o tempo total de cada uma das sessões.

Quadro 1 - Informações dos grupos focais

\begin{tabular}{|l|c|c|}
\hline \multicolumn{1}{|c|}{ Nome da instituição de ensino superior } & Número de participantes & $\begin{array}{c}\text { Tempo total do grupo } \\
\text { focal }\end{array}$ \\
\hline Universidade de Federal de Pernambuco - UFPE & 12 & $62 \mathrm{~min}$ e $53 \mathrm{seg}$ \\
\hline Universidade Federal do Pará - UFPA & 12 & $64 \mathrm{~min}$ e $40 \mathrm{seg}$ \\
\hline Universidade de Brasília - UNB & 11 & $58 \mathrm{~min}$ e $30 \mathrm{seg}$ \\
\hline Centro Universitário IPA - Porto Alegre & 9 & $61 \mathrm{~min}$ e $30 \mathrm{seg}$ \\
\hline Universidade Anhembi Morumbi - UAM & 6 & $60 \mathrm{~min}$ e 39seg \\
\hline
\end{tabular}

Fonte: Coleta de dados (2017)

Conforme se pode observar, o número de participantes variou entre 12 (UFPE e UFPA) e 6 (UAM). De acordo com Smith (2017), a maioria dos grupos focais é composta por 8 a 12 indivíduos. No entanto, ainda segundo o autor, este número pode ser menor, embora não sejam recomendados grupos com menos de 6 participantes. Quanto à duração dessas sessões, em média obteve-se um tempo aproximado de uma hora. De acordo com Gaskell (2002), em geral, os grupos focais tendem a durar entre 60 a 120 minutos. Vale salientar que, à medida que as discussões avançavam, a mediadora da sessão, acompanhada de um tópico guia que continha os principais pontos a serem discutidos, observava atentamente as opiniões do grupo. Ao mesmo tempo, tomava nota de pontos de maior interesse à pesquisa, conforme sugere Smith (2017). Além disso, com o consentimento prévio dos participantes, os áudios de todas as sessões foram gravados para auxiliar nas análises a posteriori, mediante apreciação cautelosa das transcrições das falas dos entrevistados (Gaskell,
2002).

Ao longo dos grupos focais, os participantes foram apresentados a cinco situações-problema hipotéticas,que serviram para incentivar a participação ativa do grupo na discussão (Smith, 2017). Tais situações foram elaboradas com base nas principais características das dimensões culturais de Hofstede (1980), conforme descrição seguinte:

a) Primeira situação: (Masculinidade) Tratava sobre a implementação de um resort em uma faixa de areia no litoral de um destino turístico. A gestão turística acreditava que o empreendimento aumentaria o nível de competitividade do destino.

b) Segunda situação: (Distanciamento de poder) Discutia sobre um destino turístico no qual a comunidade local não acreditava ter autoridade para modificar determinadas situações, embora estas a afetassem, elegendo outros responsáveis por resolvê-las. 
c) Terceira situação: (Individualismo) Nesta situação, os atores sociais do destino turístico não costumavam se articular na busca por melhorias, acreditando que os interesses do seu grupo deveriam ser sanados de forma particular, ainda que pudessem afetar outros agentes.

d) Quarta situação: (Aversão à incerteza) Apresentava um destino no qual os seus residentes, donos dos seus próprios negócios, se recusavam a aceitar a entrada de empreendimentos hoteleiros externos. A comunidade acreditava que a situação representava um risco desnecessário à conjuntura local.

e) Quinta situação: (Orientação ao longo prazo) Discutia acerca da chegada de cruzeiros em uma ilha que sobrevivia do turismo. A gestão turística do local acreditava que ação seria proveitosa, uma vez que acarretaria ganhos financeiros rápidos e expressivos.

\subsection{Procedimentos de análise dos dados}

À medida em que os participantes discutiam a respeito das hipóteses supramencionadas, foi possível observar a predominância de valores que indicavam sua maior ou menor propensão à cada uma das dimensões culturais de Hofstede (1980). Para identificar essas variações, foi realizado o procedimento de Análise 1, conforme ilustrado na Figura 2, identificando e contabilizando, nas falas dos participantes dos grupos focais, a ocorrência das unidades temáticas (Bardin, 1977). Com base nisso, foram identificados os traços culturais que caracterizavam cada uma das subregiões.

Ademais, os participantes também foram orientados que as situações tratavam de destinos que se auto intitulavam 'sustentáveis'. Dessa forma, foi possível analisar a imagem da sustentabilidade de destinos turísticos, averiguando se esta se deu de forma majoritariamente positiva (favorável) ou negativa (desfavorável). Para isto, levou-se em consideração, sobretudo, as menções dos participantes cujo conteúdo estava relacionado aos três pilares da sustentabilidade, quais sejam o ambiental, social e/ou econômico (Turner, Pearce \& Bateman, 1994). Novamente, as conclusões foram tomadas com base nas ocorrências das unidades temáticas, neste caso da Análise 2 (Figura 2).

O tipo de análise empregada para o estudo foi a análise de conteúdo (Bardin, 1977). No intuito de garantir maior objetividade à análise do conteúdo obtido a partir dos grupos focais, seguiu-se um processo sistemático, a começar pela seleção do esquema de unificação (Cooper e Schindler, 2016). Para tanto, optou-se por unidades temáticas, visualizadas na Figura 2, que foram desenvolvidas com base na revisão de literatura. A Análise 1, por exemplo, teve como referência o conjunto de características que definem as dimensões culturais de Hofstede (1980), enquanto a Análise 2 foi pautada no arcabouço teórico acerca da imagem. 
Figura 2 - Esquema de análise dos dados
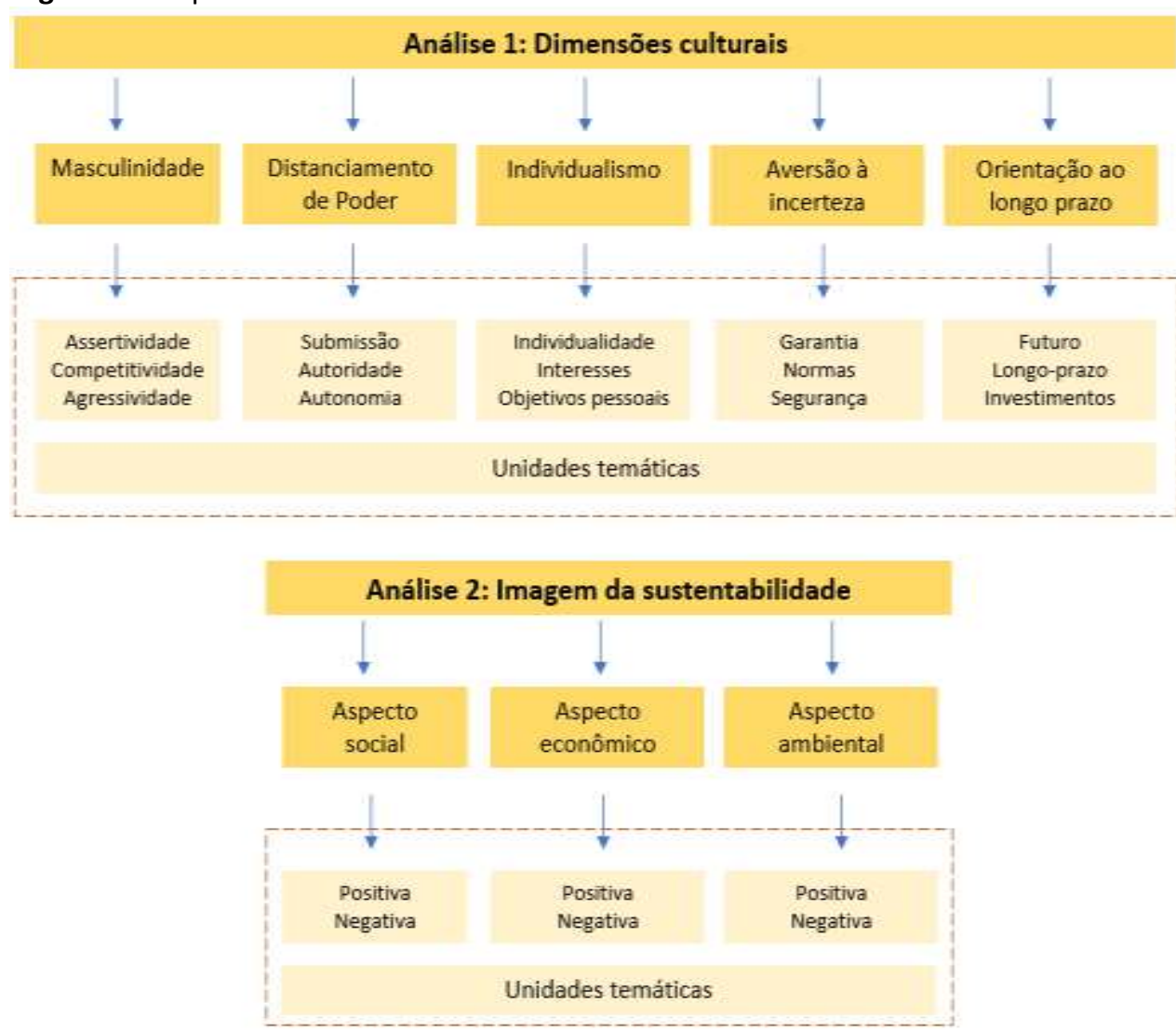

Fonte: Elaboração dos autores (2017)

Em um primeiro momento, os dados de cada grupo focal foram analisados em separado (Análise 1 e Análise 2). As informações resultantes dessa etapa preliminar serviram para concluir quanto aos aspectos de cada sub-região estudada. Em seguida, essas informações foram avaliadas de forma comparativa, resultando em uma compreensão mais holística acerca do fenômeno em questão.

\section{ANÁLISE E DISCUSSÃO DOS RESULTADOS}

Os dados apresentados nesta seção resultam dos grupos focais realizados em meio aos cinco 'Brasis', e serão apresentados seguindo a ordem em que foram coletados.
O primeiro deles foi realizado em Recife, cidade-polo representante da região cultural denominada por Ribeiro (1995) de 'Brasil Crioulo'. Conforme demonstra o Quadro 2, a seguir, os membros deste grupo tenderam a assumir posições normalmente relacionadas a sociedades com maior propensão a valores de distanciamento de poder, aversão à incerteza e orientação ao longo prazo. Por outro lado, também ficou evidente que o grupo tendeu a uma menor propensão a valores atribuídos a sociedades mais masculinas e individualistas. Já em relação à imagem da sustentabilidade dos destinos turísticos, nota-se que predominou a posição negativa por parte dos entrevistados. 
Quadro 2 - Resultados do 'Brasil Crioulo'

\begin{tabular}{|c|c|c|}
\hline \multicolumn{3}{|r|}{ Análise 1} \\
\hline Situação & Dimensão cultural & Exemplos de falas dos participantes \\
\hline \multirow{2}{*}{$\begin{array}{l}\text { Primeira } \\
\text { situação }\end{array}$} & \multirow{2}{*}{$\begin{array}{l}\text { Menor propensão à Masculini- } \\
\text { dade }\end{array}$} & $\begin{array}{l}\text { "a gestão deve implantar esse resort com uma estrutura que vai prote- } \\
\text { ger o meio ambiente, respeitando a legislação" }\end{array}$ \\
\hline & & $\begin{array}{l}\text { "vai depender diretamente de onde a comunidade local está instalada, } \\
\text { e tem que ver também se lá não é uma desova de tartarugas" }\end{array}$ \\
\hline \multirow{2}{*}{$\begin{array}{l}\text { Segunda } \\
\text { situação }\end{array}$} & \multirow{2}{*}{$\begin{array}{l}\text { Maior propensão ao Distancia- } \\
\text { mento de Poder }\end{array}$} & $\begin{array}{l}\text { "os moradores estão dando o poder pras pessoas que compraram faze- } \\
\text { rem o que quiserem" }\end{array}$ \\
\hline & & $\begin{array}{l}\text { "a comunidade perde a autoridade a partir do momento em que vende } \\
\text { a propriedade" }\end{array}$ \\
\hline \multirow{2}{*}{$\begin{array}{l}\text { Terceira } \\
\text { situação }\end{array}$} & \multirow{2}{*}{$\begin{array}{l}\text { Menor propensão ao Individua- } \\
\text { lismo }\end{array}$} & $\begin{array}{l}\text { "um dos impactos é o conflito de interesses, visto que cada uma está } \\
\text { defendendo os seus interesses" }\end{array}$ \\
\hline & & $\begin{array}{l}\text { "acho que a primeira coisa pra olhar é o consenso, é a base pra se rees- } \\
\text { truturar" }\end{array}$ \\
\hline \multirow{2}{*}{$\begin{array}{l}\text { Quarta } \\
\text { situação }\end{array}$} & \multirow{2}{*}{$\begin{array}{l}\text { Maior propensão a Aversão à } \\
\text { Incerteza }\end{array}$} & $\begin{array}{l}\text { "não necessariamente melhorar significa trazer novos hotéis, pode tam- } \\
\text { bém ajustar aquilo que já tem, capacitar as pessoas" }\end{array}$ \\
\hline & & $\begin{array}{l}\text { "incentivar a comunidade a permanecer com esse tipo de turismo, pra } \\
\text { não se perder com o tempo" }\end{array}$ \\
\hline \multirow{2}{*}{$\begin{array}{l}\text { Quinta } \\
\text { situação }\end{array}$} & \multirow{2}{*}{$\begin{array}{l}\text { Maior propensão a Orientação } \\
\text { ao Longo Prazo }\end{array}$} & $\begin{array}{l}\text { "mesmo que tenha esse retorno financeiro rápido e expressivo, eu não } \\
\text { acho que isso seja o mais importante" }\end{array}$ \\
\hline & & "tem que pensar na evolução do local, não só na questão financeira" \\
\hline \multicolumn{3}{|r|}{ Análise 2} \\
\hline Situação & Imagem da sustentabilidade & Exemplos de falas dos participantes \\
\hline \multirow{2}{*}{$\begin{array}{l}\text { Primeira } \\
\text { situação }\end{array}$} & \multirow[b]{2}{*}{ Predominantemente negativa } & "os moradores daquele local iriam trabalhar em funções mais baixas" \\
\hline & & $\begin{array}{l}\text { "a construção do resort poderá trazer efeitos negativos para a comuni- } \\
\text { dade local" }\end{array}$ \\
\hline \multirow{2}{*}{$\begin{array}{l}\text { Segunda } \\
\text { situação }\end{array}$} & \multirow{2}{*}{ Predominantemente negativa } & $\begin{array}{l}\text { "isso é muito ruim pros moradores porque é como se fosse uma inva- } \\
\text { são" }\end{array}$ \\
\hline & & $\begin{array}{l}\text { "o turismo está começando a marginalizar as pessoas que moram nesse } \\
\text { lugar" }\end{array}$ \\
\hline \multirow{2}{*}{$\begin{array}{l}\text { Terceira } \\
\text { situação }\end{array}$} & \multirow{2}{*}{ Predominantemente negativa } & $\begin{array}{l}\text { "dessa forma já mostra que de sustentável não tem nada, né? Zero sus- } \\
\text { tentabilidade" }\end{array}$ \\
\hline & & $\begin{array}{l}\text { "acho que é só uma questão de tempo pra esse destino ser levado a } \\
\text { morte, não tem como" }\end{array}$ \\
\hline \multirow{2}{*}{$\begin{array}{l}\text { Quarta } \\
\text { situação }\end{array}$} & \multirow{2}{*}{ Predominantemente negativa } & $\begin{array}{l}\text { "se entrar uma rede hoteleira aí, vai prejudicar o negócio dos morado- } \\
\text { res" }\end{array}$ \\
\hline & & $\begin{array}{l}\text { "se vierem novos empreendimentos, vai quebrar o destino e a comuni- } \\
\text { dade" }\end{array}$ \\
\hline \multirow{2}{*}{$\begin{array}{l}\text { Quinta } \\
\text { situação }\end{array}$} & \multirow{2}{*}{ Predominantemente negativa } & $\begin{array}{l}\text { "eu acho isso insustentável, os empresários só tão querendo ganhar di- } \\
\text { nheiro e mais nada" }\end{array}$ \\
\hline & & $\begin{array}{l}\text { "não adianta colocar várias pessoas no local se ele não suporta tanta } \\
\text { gente" }\end{array}$ \\
\hline
\end{tabular}

Fonte: Coleta de dados (2017) 
Ao serem apresentados à primeira situação hipotética, que tratava da implantação de um resort em uma faixa de areia de um destino turístico, o grupo, de modo geral, demonstrou priorizar elementos como a harmonia entre os atores sociais e a qualidade de vida dos moradores. Ao mencionar que o estabelecimento do resort "vai depender diretamente de onde a comunidade local está instalada, e tem que ver também se lá não é uma desova de tartarugas", um dos participantes aparentou ter certa preocupação com a qualidade de vida dos locais que residem no destino. De acordo com Hofstede (2001), esta é uma das características de sociedades cujos valores culturais apontam para uma menor propensão à masculinidade. Portanto, sociedades predominantemente femininas, em termos culturais.

Além disso, a sub-região 'Brasil Crioulo' tendeu a apresentar uma imagem predominantemente negativa quanto à sustentabilidade de destinos turísticos. Isto porque, em geral, os participantes do estudo se mostraram mais insatisfeitos com a implementação de um resort, levando-os a expor pontos de vistas mais críticos e cautelosos a respeito do assunto. Um dos participantes foi categórico ao afirmar que, com a chegada de um resort ao destino, os moradores da localidade "iriam trabalhar em funções mais baixas". Já um segundo participante chegou a ser ainda mais incisivo ao defender que "a construção do resort poderá trazer efeitos negativos para a comunidade local". Em ambos os casos, é possível observar opiniões negativas, especialmente no que se refere ao aspecto social do destino.

Nesta sub-região, houve, portanto, a predominância de valores comumente atribuídos a grupos sociais com maior propensão à feminilidade. Em paralelo, apresentou uma imagem mais negativa quanto à sustentabilidade de destinos turísticos. Geralmente, sociedades mais femininas são representadas pela sua sensibilidade e tendência a primar pela qualidade de vida (Hofstede, 2001). Características estas que podem ter originado a imagem predominantemente crítica do grupo, especialmente ao considerar que o aspecto social foi o mais evidenciado.

Já o segundo grupo focal foi realizado em Belém, cidade-polo representante da região cultural denominada por Ribeiro (1995) de 'Brasil Caboclo'. O Quadro 3, a seguir, mostra que os membros deste grupo tenderam a assumir posições normalmente relacionadas a sociedades com maior grau de aversão à incerteza e orientação ao longo prazo. Ao mesmo tempo, percebe-se que o grupo tendeu a uma menor propensão a valores atribuídos a sociedades mais masculinas, individualistas e tolerantes à distribuição desigual do poder. No que tange à imagem da sustentabilidade dos destinos turísticos, nota-se que, assim como ocorreu com o primeiro grupo, também predominou a posição negativa por parte dos entrevistados. 
Quadro 3 - Resultados do 'Brasil Caboclo'

\begin{tabular}{|c|c|c|}
\hline \multicolumn{3}{|r|}{ Análise 1} \\
\hline Situação & Dimensão cultural & Exemplos de falas dos participantes \\
\hline \multirow{2}{*}{$\begin{array}{l}\text { Primeira } \\
\text { situação }\end{array}$} & \multirow{2}{*}{$\begin{array}{l}\text { Menor propensão à Masculi- } \\
\text { nidade }\end{array}$} & $\begin{array}{l}\text { "pensar com a comunidade se seria um desenvolvimento econômico lo- } \\
\text { cal ou se seria somente um crescimento econômico pro empresário" }\end{array}$ \\
\hline & & $\begin{array}{l}\text { "o turismo poderia estar gerando uma renda mais local ao invés de só } \\
\text { para os empresários" }\end{array}$ \\
\hline \multirow{2}{*}{$\begin{array}{l}\text { Segunda } \\
\text { situação }\end{array}$} & \multirow{2}{*}{$\begin{array}{l}\text { Menor propensão ao Distan- } \\
\text { ciamento de Poder }\end{array}$} & $\begin{array}{l}\text { "importante que os moradores sintam que têm autoridade para mudar } \\
\text { essa realidade e para que eles também possam ditar as próprias regras" }\end{array}$ \\
\hline & & $\begin{array}{l}\text { "a comunidade tem que ter essa autonomia, ela pode sim mudar ou } \\
\text { tentar mudar esse destino" }\end{array}$ \\
\hline \multirow{2}{*}{$\begin{array}{l}\text { Terceira } \\
\text { situação }\end{array}$} & \multirow{2}{*}{$\begin{array}{l}\text { Menor propensão ao Indivi- } \\
\text { dualismo }\end{array}$} & $\begin{array}{l}\text { "se não tem uma conversa, um diálogo, não tem como entrar em con- } \\
\text { senso e achar uma solução" }\end{array}$ \\
\hline & & "se não houver coletividade, como nesse caso, todos saem perdendo" \\
\hline \multirow{2}{*}{$\begin{array}{l}\text { Quarta } \\
\text { situação }\end{array}$} & \multirow{2}{*}{$\begin{array}{l}\text { Maior propensão a Aversão à } \\
\text { Incerteza }\end{array}$} & $\begin{array}{l}\text { "a comunidade está indo ao poder público exigir que haja regulamenta- } \\
\text { ção para poder se prevenir" }\end{array}$ \\
\hline & & $\begin{array}{l}\text { "é importante considerar que a comunidade não deve alterar o modo } \\
\text { de vida dela para receber essas pessoas" }\end{array}$ \\
\hline \multirow{2}{*}{$\begin{array}{l}\text { Quinta } \\
\text { situação }\end{array}$} & \multirow{2}{*}{$\begin{array}{l}\text { Maior propensão a Orienta- } \\
\text { ção ao Longo Prazo }\end{array}$} & $\begin{array}{l}\text { "os gestores não podem simplesmente, por fatores financeiros, decidir } \\
\text { implementar uma ação sem pensar no futuro" }\end{array}$ \\
\hline & & $\begin{array}{l}\text { "por mais que isso dê resultados rápidos, acho que isso não é motivo } \\
\text { para permitir a ilha receber essa quantidade tão grande de turistas" }\end{array}$ \\
\hline \multicolumn{3}{|r|}{ Análise 2} \\
\hline Situação & Imagem da sustentabilidade & Exemplos de falas dos participantes \\
\hline \multirow{2}{*}{$\begin{array}{l}\text { Primeira } \\
\text { situação }\end{array}$} & \multirow{2}{*}{$\begin{array}{l}\text { Predominantemente nega- } \\
\text { tiva }\end{array}$} & $\begin{array}{l}\text { "só pelo simples fato de ser um grande resort, a primeira coisa que vai } \\
\text { causar é um dano ambiental" }\end{array}$ \\
\hline & & "eu acho que os resultados serão mais negativos do que positivos" \\
\hline \multirow{2}{*}{$\begin{array}{l}\text { Segunda } \\
\text { situação }\end{array}$} & \multirow{2}{*}{$\begin{array}{l}\text { Predominantemente nega- } \\
\text { tiva }\end{array}$} & $\begin{array}{l}\text { "o que nós podemos perceber nesse destino é apenas o interesse do } \\
\text { empresariado local, a comunidade fica excluída" }\end{array}$ \\
\hline & & "desse jeito a comunidade não vai sobreviver" \\
\hline \multirow[b]{2}{*}{$\begin{array}{l}\text { Terceira } \\
\text { situação }\end{array}$} & \multirow[b]{2}{*}{$\begin{array}{l}\text { Predominantemente nega- } \\
\text { tiva }\end{array}$} & “eu acho que não é nem um pouco sustentável essa gestão" \\
\hline & & $\begin{array}{l}\text { "nessa situação, os turistas estão deixando de visitar a localidade e o tu- } \\
\text { rismo está sendo colocado de lado" }\end{array}$ \\
\hline \multirow{2}{*}{$\begin{array}{l}\text { Quarta } \\
\text { situação }\end{array}$} & \multirow{2}{*}{ Predominantemente positiva } & $\begin{array}{l}\text { "a comunidade está se apropriando do seu espaço e está trabalhando } \\
\text { da forma que achou mais correta" }\end{array}$ \\
\hline & & $\begin{array}{l}\text { "a comunidade está certa, ela que tem que solicitar essa questão ao go- } \\
\text { verno de impedir que as empresas venham" }\end{array}$ \\
\hline \multirow[b]{2}{*}{$\begin{array}{l}\text { Quinta } \\
\text { situação }\end{array}$} & \multirow{2}{*}{$\begin{array}{l}\text { Predominantemente nega- } \\
\text { tiva }\end{array}$} & "na verdade, pode ser até um motivador de afastamento dos turistas" \\
\hline & & $\begin{array}{l}\text { "navios em uma ilha, que já não é tão grande, pode gerar danos ao } \\
\text { ecossistema" }\end{array}$ \\
\hline
\end{tabular}

Fonte: Coleta de dados (2017) 
A segunda situação hipotética criada para o estudo tratava de um destino turístico em que o poder de decisão dos diversos atores envolvidos na atividade era díspar. De forma geral, os participantes deste grupo tenderam a não aceitar essas diferenças, propondo que o pressuposto da autoridade fosse igual para todos. Na opinião deles, é necessário que os moradores "sintam que têm autoridade para mudar essa realidade para que eles também possam ditar as próprias regras". Conforme Hofstede (2001), estas são características de sociedades cujos valores culturais apontam para um menor nível de tolerância em relação ao distanciamento do poder. Destarte, sociedades que buscam por um maior equilíbrio na participação dos cidadãos em decisões que afetem a todos, ou grande parte dos seus membros.

Já no que concerne à imagem deste grupo em relação à sustentabilidade dos destinos turísticos apresentados, esta demonstrou-se predominantemente negativa. Em geral, os participantes foram críticos quanto aos três pilares da sustentabilidade. Um deles, por exemplo, apresentou a seguinte opinião: “o que nós podemos perceber nesse destino é apenas o interesse do empresariado local, a comunidade fica excluída". Também demonstrando uma má impressão em relação ao destino. Outro participante afirmou que, "desse jeito a comunidade não vai sobreviver". Em ambos os comentários, notase a insatisfação a respeito da conjuntura atual do destino.

O terceiro grupo focal foi realizado em Brasília, cidade-polo representante da sub-região denominada por Ribeiro (1995) de 'Brasil Sertanejo'. De acordo com as informações apresentadas no Quadro 4, os membros deste grupo também tenderam a assumir posições normalmente relacionadas a sociedades com maior grau de aversão à incerteza e orientação ao longo prazo. Também, de forma análoga à sub-região anterior, os participantes deste grupo voltaram-se a uma menor propensão a valores atribuídos a sociedades mais masculinas, individualistas e tolerantes à distribuição desigual do poder. Já em relação à imagem da sustentabilidade dos destinos turísticos, observa-se que, assim como ocorreu com os grupos anteriores, também predominou a posição negativa por parte dos entrevistados. 
Quadro 4-Resultados do 'Brasil Sertanejo'

\begin{tabular}{|c|c|c|}
\hline \multicolumn{3}{|r|}{ Análise 1} \\
\hline Situação & Dimensão cultural & Exemplos de falas dos participantes \\
\hline \multirow{2}{*}{$\begin{array}{l}\text { Primeira } \\
\text { situação }\end{array}$} & \multirow{2}{*}{$\begin{array}{l}\text { Menor propensão à Masculi- } \\
\text { nidade }\end{array}$} & $\begin{array}{l}\text { "o endereço desse resort deveria não impedir, ou ocupar, algo que deve- } \\
\text { ria ser visto como espaço para uso de todos" }\end{array}$ \\
\hline & & $\begin{array}{l}\text { "se a implantação desse resort acontecer, então tem que pensar na ques- } \\
\text { tão do planejamento participativo, da inserção da comunidade" }\end{array}$ \\
\hline \multirow{2}{*}{$\begin{array}{l}\text { Segunda } \\
\text { situação }\end{array}$} & \multirow{2}{*}{$\begin{array}{l}\text { Menor propensão ao Distan- } \\
\text { ciamento de Poder }\end{array}$} & $\begin{array}{l}\text { "acho que está tendo uma inércia para todos os lados, tanto da comuni- } \\
\text { dade local de não se impor como dos próprios gestores públicos" }\end{array}$ \\
\hline & & $\begin{array}{l}\text { "penso que todos devem ter poder, através do associativismo ou do coo- } \\
\text { perativismo" }\end{array}$ \\
\hline \multirow{2}{*}{$\begin{array}{l}\text { Terceira } \\
\text { situação }\end{array}$} & \multirow{2}{*}{$\begin{array}{l}\text { Menor propensão ao Indivi- } \\
\text { dualismo }\end{array}$} & $\begin{array}{l}\text { "estão pensando no crescimento econômico, mas estão esquecendo que } \\
\text { é possível trabalhar o desenvolvimento, para que todos ganhem" }\end{array}$ \\
\hline & & $\begin{array}{l}\text { "é importante que haja uma conversa, um diálogo, ainda que os interesses } \\
\text { sejam distintos" }\end{array}$ \\
\hline \multirow{2}{*}{$\begin{array}{l}\text { Quarta } \\
\text { situação }\end{array}$} & \multirow{2}{*}{$\begin{array}{l}\text { Maior propensão a Aversão à } \\
\text { Incerteza }\end{array}$} & $\begin{array}{l}\text { "é preciso, de fato, regulamentar, porque padrões na verdade precisam } \\
\text { ser respeitados" }\end{array}$ \\
\hline & & $\begin{array}{l}\text { "abrir as portas para empreendimentos de grande porte não dimensiona } \\
\text { um limite para estes investimentos" }\end{array}$ \\
\hline \multirow{2}{*}{$\begin{array}{l}\text { Quinta } \\
\text { situação }\end{array}$} & \multirow{2}{*}{$\begin{array}{l}\text { Maior propensão a Orienta- } \\
\text { ção ao Longo Prazo }\end{array}$} & $\begin{array}{l}\text { "acho que é aquele discurso que vai trazer benefícios financeiros a curto } \\
\text { prazo, só que não está pensando a longo prazo" }\end{array}$ \\
\hline & & $\begin{array}{l}\text { "a gestão deveria fazer um planejamento e pensar qual é objetivo, o que } \\
\text { estão querendo se tornar no cenário turístico" }\end{array}$ \\
\hline \multicolumn{3}{|r|}{ Análise 2} \\
\hline Situação & Imagem da sustentabilidade & Exemplos de falas dos participantes \\
\hline \multirow{2}{*}{$\begin{array}{l}\text { Primeira } \\
\text { situação }\end{array}$} & \multirow{2}{*}{ Predominantemente negativa } & $\begin{array}{l}\text { "os próprios materiais do resort prejudicam o meio ambiente e vão aca- } \\
\text { bar afetando o mar, a vida marinha" }\end{array}$ \\
\hline & & "não beneficia muito nem a comunidade, nem o meio ambiente" \\
\hline \multirow{2}{*}{$\begin{array}{l}\text { Segunda } \\
\text { situação }\end{array}$} & \multirow{2}{*}{ Predominantemente negativa } & $\begin{array}{l}\text { "os próprios empresários não estão interessados em envolver a comuni- } \\
\text { dade, eles só querem usá-los" }\end{array}$ \\
\hline & & "sem distribuição de poderes, é praticamente insustentável" \\
\hline \multirow{2}{*}{$\begin{array}{l}\text { Terceira } \\
\text { situação }\end{array}$} & \multirow[t]{2}{*}{ Predominantemente negativa } & $\begin{array}{l}\text { "é claramente insustentável, porque, no longo prazo, uma hora essa falta } \\
\text { de articulação vai se afundar" }\end{array}$ \\
\hline & & "do jeito que esse destino está, realmente não vai muito pra frente" \\
\hline \multirow{2}{*}{$\begin{array}{l}\text { Quarta } \\
\text { situação }\end{array}$} & \multirow[t]{2}{*}{ Predominantemente negativa } & $\begin{array}{l}\text { "os moradores vão virar funcionários do hotel, não vão ter uma qualidade } \\
\text { de vida tão boa" }\end{array}$ \\
\hline & & "esse turismo é não planejado e pode acabar com o que existe" \\
\hline \multirow[b]{2}{*}{$\begin{array}{l}\text { Quinta } \\
\text { situação }\end{array}$} & \multirow[b]{2}{*}{ Predominantemente negativa } & "possivelmente haverá um aumento alarmante de resíduos e detritos" \\
\hline & & $\begin{array}{l}\text { "se pensarmos na sustentabilidade, esta quantidade de navios atracados } \\
\text { nem sempre são tão benéficas assim" }\end{array}$ \\
\hline
\end{tabular}

Fonte: Coleta de dados (2017) 
Ao discutir sobre a terceira situação hipotética elaborada para o estudo, este grupo tendeu a apresentar menor propensão ao individualismo. Isto porque, no momento em que falava sobre um destino predominantemente individualista, o grupo demonstrou maior inclinação a promover um ambiente de colaboração e associação entre os membros, acreditando ser necessária a busca pela integração entre todos os atores sociais do destino. Um dos integrantes, por exemplo, demonstrou preferência por ambientes colaborativos e consensuais, ao afirmar que, no destino em questão, "é importante que haja uma conversa, um diálogo, ainda que os interesses sejam distintos". Para Hofstede (2001), esta é uma das características de sociedades cujos valores culturais apontam para uma menor propensão ao individualismo. Portanto, sociedades predominantemente coletivistas, em termos culturais.

Além disso, o 'Brasil Sertanejo', assim como as demais sub-regiões já mencionadas, também demonstrou uma imagem predominantemente negativa quanto à sustentabilidade dos destinos turísticos apresentados. De modo geral, os participantes se mostraram insatisfeitos e críticos quanto à falta de articulação que ocorre no local. A imagem de um deles em relação aos destinos aparentou ser negativa, principalmente no que diz respeito à sustentabilidade local, conforme relato a seguir: "é claramente insustentável, porque, no longo prazo, uma hora essa falta de articulação vai se afundar". Este comentário ilustra a insatisfação predominante no grupo, em especial no que tange ao aspecto social.

O quarto grupo focal, por sua vez, foi realizado na cidade-polo de Porto Alegre, representante da sub-região denominada por Ribeiro (1995) de 'Brasil Sulinas'. Conforme aponta o Quadro 5, seguinte, os membros deste grupo tenderam a assumir posições normalmente relacionadas a sociedades com maior propensão a valores de masculinidade, tolerância à distribuição desigual do poder e orientação ao longo prazo. Em contrapartida, os participantes deste grupo se voltaram a uma menor propensão a valores atribuídos a sociedades mais individualistas e avessas à incerteza. No entanto, diferentemente das sub-regiões anteriormente citadas, o 'Brasil Sulinas' apresentou, de forma geral, uma imagem predominantemente positiva quanto à sustentabilidade dos destinos turísticos apresentados. 
Quadro 5 - Resultados do 'Brasil Sulinas'

\begin{tabular}{|c|c|c|}
\hline \multicolumn{3}{|r|}{ Análise 1} \\
\hline Situação & Dimensão cultural & Exemplos de falas dos participantes \\
\hline \multirow{2}{*}{$\begin{array}{l}\text { Primeira } \\
\text { situação }\end{array}$} & \multirow{2}{*}{$\begin{array}{l}\text { Maior propensão à Masculini- } \\
\text { dade }\end{array}$} & $\begin{array}{l}\text { "um resort tem muitos funcionários e isso vai trazer emprego pro pes- } \\
\text { soal local" }\end{array}$ \\
\hline & & $\begin{array}{l}\text { "tem que pensar nas pessoas que estão alí do lado, se tiver um resort } \\
\text { lá eles vão vender mais" }\end{array}$ \\
\hline \multirow{2}{*}{$\begin{array}{l}\text { Segunda } \\
\text { situação }\end{array}$} & \multirow{2}{*}{$\begin{array}{l}\text { Maior propensão ao Distancia- } \\
\text { mento de Poder }\end{array}$} & $\begin{array}{l}\text { "no momento em que os moradores venderam as propriedades, eles } \\
\text { perderam de fato o direito de zelar por aquele espaço" }\end{array}$ \\
\hline & & $\begin{array}{l}\text { "no momento em que o morador vendeu a terra dele, ele já perdeu } \\
\text { um pouco desse direito de revogar" }\end{array}$ \\
\hline \multirow{2}{*}{$\begin{array}{l}\text { Terceira } \\
\text { situação }\end{array}$} & \multirow{2}{*}{$\begin{array}{l}\text { Menor propensão ao Individua- } \\
\text { lismo }\end{array}$} & $\begin{array}{l}\text { "o primeiro passo é o destino parar de defender o de cada um e segui- } \\
\text { rem pra entrar em um consenso" }\end{array}$ \\
\hline & & $\begin{array}{l}\text { "se as duas partes se unirem, a coisa dá certo, porque quando é uma } \\
\text { cooperativa, aí as coisas elas funcionam" }\end{array}$ \\
\hline \multirow{2}{*}{$\begin{array}{l}\text { Quarta } \\
\text { situação }\end{array}$} & \multirow{2}{*}{$\begin{array}{l}\text { Menor propensão a Aversão à } \\
\text { Incerteza }\end{array}$} & $\begin{array}{l}\text { "está dando um sustento legal para os moradores locais, mas, com a } \\
\text { chegada de hotéis, pode dar um sustento melhor para o destino" }\end{array}$ \\
\hline & & $\begin{array}{l}\text { "a comunidade precisa pensar em algo maior, o que, de repente, po- } \\
\text { derá gerar um dinheiro muito maior para o estado" }\end{array}$ \\
\hline \multirow{2}{*}{$\begin{array}{l}\text { Quinta } \\
\text { situação }\end{array}$} & \multirow{2}{*}{$\begin{array}{l}\text { Maior propensão a Orientação } \\
\text { ao Longo Prazo }\end{array}$} & $\begin{array}{l}\text { "um cruzeiro que vai descer } 2 \text { mil pessoas nessa ilha vai degradar o } \\
\text { ambiente, vai se perder com o tempo a paisagem" }\end{array}$ \\
\hline & & $\begin{array}{l}\text { "tomar essa medida pode ser, num primeiro momento, bom pro } \\
\text { bolso, mas acho que a longo prazo é inviável" }\end{array}$ \\
\hline \multicolumn{3}{|r|}{ Análise 2} \\
\hline Situação & Imagem da sustentabilidade & Exemplos de falas dos participantes \\
\hline \multirow{2}{*}{$\begin{array}{l}\text { Primeira } \\
\text { situação }\end{array}$} & \multirow[b]{2}{*}{ Predominantemente positiva } & "eu acho que, economicamente, o destino só tem a ganhar" \\
\hline & & $\begin{array}{l}\text { "na medida em que conseguir planejar bem, acho que um resort só } \\
\text { pode agregar nessa situação" }\end{array}$ \\
\hline \multirow{2}{*}{$\begin{array}{l}\text { Segunda } \\
\text { situação }\end{array}$} & \multirow{2}{*}{ Predominantemente positiva } & $\begin{array}{l}\text { "em termos de sustentabilidade, esse destino é muito melhor, mais } \\
\text { sustentável" }\end{array}$ \\
\hline & & $\begin{array}{l}\text { "eu acho que, nesse exemplo, tende a ser mais favorável pra comuni- } \\
\text { dade, pro destino" }\end{array}$ \\
\hline \multirow{2}{*}{$\begin{array}{l}\text { Terceira } \\
\text { situação }\end{array}$} & \multirow{2}{*}{ Predominantemente negativa } & "não está acontecendo uma coisa legal, não tá sendo sustentável" \\
\hline & & "quando cada um quer fazer o seu, não tem sustentabilidade" \\
\hline \multirow{2}{*}{$\begin{array}{l}\text { Quarta } \\
\text { situação }\end{array}$} & \multirow{2}{*}{ Predominantemente positiva } & $\begin{array}{l}\text { "se for implantada uma infraestrutura diferenciada e movimentar } \\
\text { mais pessoas, mais dinheiro para o estado" }\end{array}$ \\
\hline & & $\begin{array}{l}\text { "isso se chama sustentabilidade, acho esse projeto válido porque já } \\
\text { existe uma subsistência no local" }\end{array}$ \\
\hline \multirow{2}{*}{$\begin{array}{l}\text { Quinta } \\
\text { situação }\end{array}$} & \multirow{2}{*}{ Predominantemente negativa } & $\begin{array}{l}\text { "vendo o custo-benefício acho que seria incoerente, uma vez que é } \\
\text { muita gente em um período curto de tempo" }\end{array}$ \\
\hline & & $\begin{array}{l}\text { "vai se deteriorar a imagem do destino, causando impactos muito ne- } \\
\text { gativos" }\end{array}$ \\
\hline
\end{tabular}

Fonte: Coleta de dados (2017) 
Na quarta situação hipotética criada para o estudo, tratava-se de um destino turístico no qual os residentes eram contrários à entrada de empreendimentos hoteleiros externos. Isso porque, para eles, a ação representaria riscos desnecessários e imprevisíveis. Diante disso, o grupo tendeu a não concordar com a oposição da comunidade, acreditando que a exposição aos riscos é necessária por representar a possibilidade de melhorias para o destino. Isto foi o que enfatizou um dos participantes, ao comentar que a situação "está dando um sustento legal para os moradores locais, mas, com a chegada de hotéis, pode dar um sustento melhor para o destino". Conforme Hofstede (2001), a exposição a situações imprevisíveis e a mudanças são algumas das características comumente encontradas em sociedades com menor propensão à aversão a incertezas.

Em paralelo, esta sub-região demonstrou possuir uma imagem mais positiva quanto à sustentabilidade dos destinos turísticos apresentados, também contrariando as demais sub-regiões. Ao discutirem acerca da entrada de capital e investimento externo, os participantes, de forma geral, enxergaram a situação como sendo oportuna e benéfica para a localidade. Um deles chegou a afirmar que "se for implantada uma infraestrutura diferenciada e movimentar mais pessoas, mais dinheiro para o estado", se mostrando positivo em relação às mudanças, especialmente levando em consideração a economia local.

Por fim, o quinto e último grupo focal foi realizado em São Paulo, cidade-polo representante da região cultural denominada por Ribeiro (1995) de 'Brasil Caipira'. O Quadro 6, a seguir, mostra que os membros deste grupo tenderam a assumir posições normalmente relacionadas a sociedades com maior grau de aversão à incerteza e orientação ao longo prazo. Contudo, os participantes deste grupo estavam voltados a uma menor propensão a valores atribuídos a sociedades mais masculinas, individualistas e tolerantes à distribuição desigual do poder. No que diz respeito à imagem da sustentabilidade dos destinos turísticos, observa-se que, assim como a maioria das sub-regiões anteriores (exceto o 'Brasil Sulinas'), também predominou a posição negativa por parte dos entrevistados. 
Quadro 6-Resultados do 'Brasil Caipira'

\begin{tabular}{|c|c|c|}
\hline \multicolumn{3}{|r|}{ Análise 1} \\
\hline Situação & Dimensão cultural & Exemplos de falas dos participantes \\
\hline \multirow{2}{*}{$\begin{array}{l}\text { Primeira } \\
\text { situação }\end{array}$} & \multirow{2}{*}{$\begin{array}{l}\text { Menor propensão à Masculini- } \\
\text { dade }\end{array}$} & $\begin{array}{l}\text { "com certeza vai gerar especulação imobiliária, o que fará com que os } \\
\text { moradores da região não possam mais morar lá" }\end{array}$ \\
\hline & & $\begin{array}{l}\text { "a eficácia depende se o resort vai ter estrutura para manter o meio } \\
\text { ambiente bem, se vai ter estrutura para cuidar da qualidade de vida" }\end{array}$ \\
\hline \multirow{2}{*}{$\begin{array}{l}\text { Segunda } \\
\text { situação }\end{array}$} & \multirow{2}{*}{$\begin{array}{l}\text { Menor propensão ao Distancia- } \\
\text { mento de Poder }\end{array}$} & $\begin{array}{l}\text { "os moradores têm que dar opinião sobre o que eles querem, sobre } \\
\text { como que vai instalar as coisas lá" }\end{array}$ \\
\hline & & $\begin{array}{l}\text { "os moradores não podem se submeter a não ter poder porque al- } \\
\text { guém está comprando imóveis" }\end{array}$ \\
\hline \multirow{2}{*}{$\begin{array}{l}\text { Terceira } \\
\text { situação }\end{array}$} & \multirow{2}{*}{$\begin{array}{l}\text { Menor propensão ao Individua- } \\
\text { lismo }\end{array}$} & $\begin{array}{l}\text { "acho que todos tem que pensar em coletivo para que o turismo lá } \\
\text { seja bom" }\end{array}$ \\
\hline & & "tem que abranger todos os pontos, com todo mundo opinando" \\
\hline \multirow{2}{*}{$\begin{array}{l}\text { Quarta } \\
\text { situação }\end{array}$} & \multirow{2}{*}{$\begin{array}{l}\text { Maior propensão a Aversão à In- } \\
\text { certeza }\end{array}$} & $\begin{array}{l}\text { "a gestão pode desenvolver as hospedagens sem tirar ou mudar suas } \\
\text { identidades, não precisa ser um hotel novo" }\end{array}$ \\
\hline & & $\begin{array}{l}\text { "risco nessa situação é colocar um monte de hotel e acabar com a } \\
\text { identidade do local" }\end{array}$ \\
\hline \multirow{2}{*}{$\begin{array}{l}\text { Quinta } \\
\text { situação }\end{array}$} & \multirow{2}{*}{$\begin{array}{l}\text { Maior propensão a Orientação } \\
\text { ao Longo Prazo }\end{array}$} & $\begin{array}{l}\text { "tem que pensar na vida marinha ao longo do tempo, para que não se } \\
\text { perca a essência do destino ao afetar o seu bioma" }\end{array}$ \\
\hline & & $\begin{array}{l}\text { "é algo que traz um benefício econômico rápido, mas os aspectos am- } \\
\text { bientais de longo prazo também são muito importantes" }\end{array}$ \\
\hline \multicolumn{3}{|r|}{ Análise 2} \\
\hline Situação & Imagem da sustentabilidade & Exemplos de falas dos participantes \\
\hline \multirow{2}{*}{$\begin{array}{l}\text { Primeira } \\
\text { situação }\end{array}$} & \multirow{2}{*}{ Predominantemente negativa } & $\begin{array}{l}\text { "o resort pode até ter algum projeto para tentar amenizar efeitos ne- } \\
\text { gativos, mas não vai ser a mesma coisa de quando não tinha nada ali" }\end{array}$ \\
\hline & & $\begin{array}{l}\text { "isso pode prejudicar o ambiente marinho e a própria população, por- } \\
\text { que vai haver alguma influência" }\end{array}$ \\
\hline \multirow{2}{*}{$\begin{array}{l}\text { Segunda } \\
\text { situação }\end{array}$} & \multirow[b]{2}{*}{ Predominantemente negativa } & $\begin{array}{l}\text { "essa situação vai impactar negativamente a vida da comunidade lo- } \\
\text { cal" }\end{array}$ \\
\hline & & $\begin{array}{l}\text { "a partir do momento em que os moradores se submetem a não ter } \\
\text { poder porque alguém está comprando os seus imóveis, não é susten- } \\
\text { tável" }\end{array}$ \\
\hline \multirow{2}{*}{$\begin{array}{l}\text { Terceira } \\
\text { situação }\end{array}$} & \multirow[b]{2}{*}{ Predominantemente negativa } & "eu acho que se não pensar todo mundo junto vai virar uma zona" \\
\hline & & $\begin{array}{l}\text { "esse destino tá fracassado, sem conversa não tem como chegar a lu- } \\
\text { gar nenhum" }\end{array}$ \\
\hline \multirow{2}{*}{$\begin{array}{l}\text { Quarta } \\
\text { situação }\end{array}$} & \multirow[t]{2}{*}{ Predominantemente negativa } & $\begin{array}{l}\text { "se chegar um hotel e vierem turistas que preferem o conforto do ho- } \\
\text { tel, os moradores vão perder totalmente a renda deles" }\end{array}$ \\
\hline & & "vai perder o atrativo principal do local, que é a sua identidade" \\
\hline \multirow{2}{*}{$\begin{array}{l}\text { Quinta } \\
\text { situação }\end{array}$} & \multirow{2}{*}{ Predominantemente negativa } & $\begin{array}{l}\text { "o turista pode almoçar no navio, não usar os restaurantes locais e } \\
\text { ainda deixar lixo e esgoto na ilha" }\end{array}$ \\
\hline & & $\begin{array}{l}\text { "o navio vai ficar três dias parados em alto mar e isto pode afetar ne- } \\
\text { gativamente o ecossistema local" }\end{array}$ \\
\hline
\end{tabular}

Fonte: Coleta de dados (2017) 
As análises que foram realizadas a partir da quinta e última situação hipotética indicaram que, a princípio, a sub-região 'Brasil Caipira' possui características predominantes de sociedades com maior propensão à orientação ao longo prazo. Isto porque, ao discutirem a respeito da possibilidade de cruzeiros ficarem atracados em uma ilha turística, os participantes deste grupo se mostraram preocupados com as consequências futuras desta ação. Para um dos participantes, os gestores do destino "têm que pensar na vida marinha ao longo do tempo, para que não se perca a essência do destino ao afetar o seu bioma", demonstrando sua preocupação com a conjuntura do destino no futuro.

Em paralelo, apresentando resultados análogos aos que foram encontrados na maioria das sub-regiões, esta região cultural também demonstrou ter uma imagem mais negativa quanto à sustentabilidade dos destinos turísticos apresentados. Ao tratar a respeito da chegada de cruzeiros na ilha, um dos participantes afirmou que "o turista pode al- moçar no navio, não usar os restaurantes locais e ainda deixar lixo e esgoto na ilha", deixando evidente sua insatisfação com a entrada de navios no destino, em especial se tratando das questões socioambientais no local. Este ponto de vista de caráter reprobatório ilustra a interpretação que foi predominante no grupo, isto é, mais negativa.

A partir dos dados que foram apresentados a respeito das cinco sub-regiões do Brasil, o Quadro 7 foi elaborado como síntese dos resultados obtidos. Nele, as siglas 'MAS, PDI, IDV, UAI e LTO' correspondem às dimensões da Masculinidade, Distanciamento de Poder, Individualismo, Aversão à Incerteza e Orientação ao Longo Prazo - mantidas em sua versão original, conforme proposição de Hofstede (1980). Pode-se observar que os resultados se mostraram bastante semelhantes na maioria das sub-regiões. Entretanto, o 'Brasil Sulinas' apresentou diferenças notórias, tanto no âmbito das dimensões culturais como no que se refere à imagem da sustentabilidade. 
Quadro 7 - Síntese dos resultados da pesquisa

\begin{tabular}{|l|l|l|l|l|l|l|}
\hline \multirow{2}{*}{ Sub-região } & \multicolumn{5}{|c|}{ Dimensões culturais } & \multicolumn{1}{c|}{$\begin{array}{l}\text { Imagem da } \\
\text { sustentabilidade }\end{array}$} \\
\cline { 2 - 6 } & MAS & \multicolumn{1}{|c|}{ PDI } & \multicolumn{1}{|c|}{ IDV } & UAI & \multicolumn{1}{|c|}{ LTo } & \\
\hline $\begin{array}{l}\text { Brasil } \\
\text { Crioulo }\end{array}$ & $\begin{array}{l}\text { Menor } \\
\text { propensão }\end{array}$ & $\begin{array}{l}\text { Maior pro- } \\
\text { pensão }\end{array}$ & $\begin{array}{l}\text { Menor pro- } \\
\text { pensão }\end{array}$ & $\begin{array}{l}\text { Maior pro- } \\
\text { pensão }\end{array}$ & $\begin{array}{l}\text { Maior pro- } \\
\text { pensão }\end{array}$ & $\begin{array}{l}\text { Predominantemente } \\
\text { negativa }\end{array}$ \\
\hline $\begin{array}{l}\text { Brasil } \\
\text { Caboclo }\end{array}$ & $\begin{array}{l}\text { Menor } \\
\text { propensão }\end{array}$ & $\begin{array}{l}\text { Menor } \\
\text { propensão }\end{array}$ & $\begin{array}{l}\text { Menor pro- } \\
\text { pensão }\end{array}$ & $\begin{array}{l}\text { Maior pro- } \\
\text { pensão }\end{array}$ & $\begin{array}{l}\text { Maior pro- } \\
\text { pensão }\end{array}$ & $\begin{array}{l}\text { Predominantemente } \\
\text { negativa }\end{array}$ \\
\hline $\begin{array}{l}\text { Brasil } \\
\text { Sulinas }\end{array}$ & $\begin{array}{l}\text { Maior pro- } \\
\text { pensão }\end{array}$ & $\begin{array}{l}\text { Maior pro- } \\
\text { pensão }\end{array}$ & $\begin{array}{l}\text { Menor pro- } \\
\text { pensão }\end{array}$ & $\begin{array}{l}\text { Menor pro- } \\
\text { pensão }\end{array}$ & $\begin{array}{l}\text { Maior pro- } \\
\text { pensão }\end{array}$ & $\begin{array}{l}\text { Predominantemente } \\
\text { positiva }\end{array}$ \\
\hline $\begin{array}{l}\text { Brasil } \\
\text { Sertanejo }\end{array}$ & $\begin{array}{l}\text { Menor } \\
\text { propensão }\end{array}$ & $\begin{array}{l}\text { Menor } \\
\text { propensão }\end{array}$ & $\begin{array}{l}\text { Menor pro- } \\
\text { pensão }\end{array}$ & $\begin{array}{l}\text { Maior pro- } \\
\text { pensão }\end{array}$ & $\begin{array}{l}\text { Maior pro- } \\
\text { pensão }\end{array}$ & $\begin{array}{l}\text { Predominantemente } \\
\text { negativa }\end{array}$ \\
\hline $\begin{array}{l}\text { Brasil } \\
\text { Caipira }\end{array}$ & $\begin{array}{l}\text { Menor } \\
\text { propensão }\end{array}$ & $\begin{array}{l}\text { Menor } \\
\text { propensão }\end{array}$ & $\begin{array}{l}\text { Menor pro- } \\
\text { pensão }\end{array}$ & $\begin{array}{l}\text { Maior pro- } \\
\text { pensão }\end{array}$ & $\begin{array}{l}\text { Maior pro- } \\
\text { pensão }\end{array}$ & $\begin{array}{l}\text { Predominantemente } \\
\text { negativa }\end{array}$ \\
\hline
\end{tabular}

Fonte: Coleta de dados (2017)

Observa-se no Quadro 7 que, embora defendido por Ribeiro (1995) que o Brasil seja composto por uma multiplicidade cultural evidente, tais diferenças não se mostraram tão acentuadas quando analisadas sob a ótica das dimensões culturais de Hofstede (1980). De modo comparativo, percebeu-se que somente a sub-região 'Brasil Sulinas' apresentou maiores discrepâncias em relação às demais. Os dados analisados neste estudo revelaram que, exclusivamente naquela sub-região, houve maior predominância de valores culturais comumente associados a grupos com elevados índices de masculinidade. Em contrapartida, o nível de aversão à incerteza identificado neste mesmo grupo se mostrou abaixo daquele comumente encontrado nas outras sub-regiões do Brasil.

Vale salientar que as diferenças evidenciadas de forma mais expressiva apenas pelo 'Brasil Sulinas' podem ser explicadas pela influência que algumas culturas nacionais externas exerceram, e ainda exercem, especificamente nesta região. Segundo o próprio Ribeiro (1995), esta é uma das localidades que mais acolheu indivíduos de diferentes identidades nacionais, especialmente de imigrantes europeus com origem não lusitanas. Os alemães e os italianos, por exemplo, estão presentes no processo de formação sulista desde muito tempo, o que provocou influência significativa destas nacionalidades nos âmbitos econômico, social e cultural da região (Cunha \& Gartner, 2003; Giron \& Herédia, 2007; Trombini, 2017). Este mesmo fato, entretanto, não ocorreu de forma tão expressiva nas demais regiões do país, refletindo formas e hábitos particulares aos sulistas (Neto \& Bezzi, 2007).

No que diz respeito à imagem dos consumidores em relação à sustentabilidade dos destinos turísticos apresentados, a maioria das sub-regiões tendeu a interpretar tal elemento de forma predominantemente negativa. Ao serem confrontados com a pretensão dos destinos hipotéticos em criar uma 
identidade local com base na sustentabilidade, grande parte dos 'Brasis' demonstrouse cético e pouco atraído pelo apelo. Destaca-se, ainda, que o aspecto da sustentabilidade de maior relevância para estes foi o social, em detrimento do ambiental e do econômico. Já o 'Brasil Sulinas' foi o único que tendeu a se posicionar de forma mais otimista frente à identidade sustentável dos destinos turísticos hipotéticos, especialmente no que se refere à esfera econômica da sustentabilidade.

Com base nestes resultados, fica claro que é possível atribuir a imagem dos consumidores brasileiros em relação à sustentabilidade dos destinos turísticos às características da sua região cultural de origem. Apesar disso, reconhece-se que ainda são necessários estudos mais específicos e aprofundados sobre o tema, a fim de confrontar as conclusões apresentadas nesta pesquisa. A princípio, é provável que a maior propensão para a masculinidade e à menor aversão a incertezas, características que foram encontradas apenas no 'Brasil Sulinas', possam explicar a tendência a uma imagem mais positiva por parte dos representantes desta sub-região.

Para Hofstede (2001), grupos sociais cujos valores revelam uma maior propensão à masculinidade tendem a ser autoconfiantes e primar pela competitividade. Estas características, reveladas somente nesta sub-região, podem explicar a predominância de uma imagem mais positiva no tocante ao aspecto econômico da sustentabilidade. Ao mesmo tempo, sociedades com a predominância de atributos que indicam menores índices de aversão à incerteza, como no caso do 'Brasil Sulinas', tendem a ser mais seguras e abertas a novas oportunidades. Esta também pode ser a razão para a interpretação menos cautelosa e predominantemente otimista deste grupo em relação ao futuro dos destinos turísticos apresentados.

Por outro lado, as características culturais que foram identificadas nas demais sub-regiões também podem explicar a imagem mais negativa destes grupos quanto à sustentabilidade dos destinos turísticos. A princípio, estas sub-regiões indicaram menor propensão à masculinidade, o que, conforme o suporte teórico desta investigação, tende a revelar sociedades que primam pela qualidade de vida e pela harmonia. Atributos como estes, podem fomentar uma visão mais crítica em relação à sustentabilidade de destinos turísticos, especialmente no que diz respeito ao aspecto social. Além disso, apresentaram maior aversão à incerteza ao revelar insegurança, insatisfação com mudanças e pouca tolerância aos possíveis riscos, o que pode ter direcionado a uma visão mais crítica e cautelosa por parte deste grupo.

\section{CONCLUSÕES}

Esta investigação conclui que, no caso do Brasil, regiões caracterizadas pelas mesmas dimensões culturais tendem a uma interpretação semelhante no tocante à sustentabilidade de destinos turísticos. Isto porque os resultados destacaram que a única região brasileira com traços culturais mais diferentes das demais foi, também, a única que apresentou uma imagem mais positiva, em contraposição às outras sub-regiões. Portanto, foi perceptível que, no território brasileiro, a imagem da sustentabilidade de destinos turísticos tendeu a ser influenciada pelos traços culturais das sub-regiões de origem 
dos consumidores.

Entende-se que, ao pensar sobre as estratégias de marketing mais eficazes, os gestores de destinos turísticos devam levar em conta as particularidades culturais dos consumidores potenciais. Vale salientar que, no caso da atividade turística, esta segmentação com base cultural é ainda mais pertinente, uma vez que os destinos lidam diariamente com turistas provenientes de diversas regiões culturais. De tal modo, ao assumir a identidade sustentável, as destinações devem compreender de que forma os consumidores, influenciados pelos seus traços culturais, interpretam este argumento. Assim, poderão empregar ações e estratégias de marketing mais direcionadas e condizentes com as características dos seus mercados-alvo. Tal abordagem vai ao encontro do que sugerem autores como Kavaratzis (2005) e Warren \&Dinner (2018) quanto à aplicação de preceitos do place marketing e doplace branding, aparentemente ainda pouco explorados no mercado brasileiro.

Em linhas gerais, esta investigação conclui que a maioria das sub-regiões do Brasil, além de possuir padrões culturais semeIhantes, tende a interpretar similarmente a sustentabilidade de destinos turísticos. Isto indica que um único esforço de marketing poderia resultar em um retorno similar entre as sub-regiões do Brasil, com exceção do 'Brasil Sulinas'. Em função da imagem mais negativa evidenciada na maioria das regiões, é possível que, nestes casos, as ações de marketing precisem ser mais robustas, de forma a convencer estes consumidores de que o argumento 'sustentável' empregado pelos destinos é pertinente. Além disso, os gestores devem levar em conta que o aspecto social foi o que mais chamou a atenção destes consumidores.

Ao mesmo tempo, a divergência apresentada pelo 'Brasil Sulinas' revelou que, no caso desta região cultural específica, os esforços de marketing devem ser orientados de maneira um pouco diferente. Em função da imagem predominantemente positiva que este grupo apresentou, é possível que as ações dos gestores já não tenham a necessidade ser tão elaboradas quanto nas demais sub-regiões, uma vez que este grupo é, por natureza, mais otimista. Ao mesmo tempo, precisam considerar que, neste caso, o aspecto econômico foi o mais enaltecido pelos consumidores.

Assim como em toda investigação, este estudo também se deparou com algumas limitações, muito embora elas não tenham influenciado o alcance dos objetivos propostos. A princípio, vale salientar que os grupos focais realizados por vídeo-chamadas impossibilitaram uma observação mais detaIhada da interação entre os participantes. Além disso, a seleção por conveniência de estudantes de áreas comuns à hospitalidade pode não ter sido o suficiente para representar a opinião de toda população que compõe os 'Brasis', havendo a necessidade de estudos complementares para complementar os achados desta pesquisa. Por fim, em função do objetivo de traçar um panorama geral da relação entre cultura e imagem de destinos turísticos, não foi possível investigar determinadas variações, a exemplo da que ocorreu na dimensão 'Distanciamento de Poder' .

Enquanto sugestões para futuras pesquisas, a princípio recomenda-se utilizar esta investigação como ponto de partida para estudos mais direcionados à realidade de cada 
uma das regiões culturais do Brasil. Além disso, sugere-se, também, utilizar outros métodos de coleta, a exemplo das entrevistas, ou até mesmo direcionar a análise para outra dimensão de uma marca de país ou região, que não seja a sustentabilidade. Por fim, acredita-se na possibilidade de realizar outros estudos com objetivos semelhantes ao que foi empregado nesta pesquisa, de preferência em grupos nacionais que também sejam formados por diferentes regiões culturais. A partir de então, é possível, inclusive, realizar uma análise comparativa.

\section{AGRADECIMENTO}

Os autores agradecem ao Conselho Nacional de Desenvolvimento Científico e Tecnológico - CNPq pela concessão de Bolsa de Iniciação Científica para o desenvolvimento desta pesquisa.

\section{REFERÊNCIAS}

Aaker, D. A. (2004) Leve raging the corporatebrand. California management review, 46(3), 6-18. DOI: https://doi.org/10.1177/000812560404600301

Andrade, M., Barbosa, M., Souza, A. (2010) A sustentabilidade socioambiental presente na composição da identidade do Arquipélago de Fernando de Noronha e sua influência como fator de promoção turística. Revista de Investigaciónen Turismo y Desarrolo Local, 6, 1-18.

Bardin, L. (1977) Análise de conteúdo. Lisboa, Portugal: Edições 70

Bonn, M., Joseph, S., Dai, M. (2005) International versus domestic visitors: examination of destination image perceptions. Journal of Travel Research, 43(3), 294-301. DOI: https://doi.org/10.1177/0047287504272033
Brewer, P., Venaik, S. (2012) On the misuse of national culture dimensions. International Marketing Review, 29(6), 673-683. DOI: https://doi.org/10.1108/02651331211277991

Buhalis, D. (2000) Marketing the competitive destination of the future. Tourism Management, 21, 97-116. DOI: https://doi.org/10.1016/S0261$\underline{5177(99) 00095-3}$

Conner, T. S., Tennen, H., Fleeson, W., \& Barrett, L. F. (2009) Experience sampling methods: A modern idiographic approach to personality research. Social and personality psychology compass, 3(3), 292-313. DOI: https://doi.org/10.1111/j.1751-9004.2009.00170.x

Cooper, D., Schindler, P. (2016) Métodos de pesquisa em administração. Amgh, Porto Alegre.

Cucculelli, M., \&Goffi, G. (2016) Does sustainability enhance tourism destination competitiveness? Evidence from Italian Destinations of Excellence. Journal of Cleaner Production, 111, 370-382. DOI: https://doi.org/10.1016/j.jclepro.2014.12.069

Cunha, J., Gärtner, A. (2003) Imigração alemã no Rio Grande do Sul: história, linguagem, educação. Editora UFSM, Santa Maria.

Dinnie, K. (2015) Nation branding: Concepts, issues, practice. Routledge, Londres, Reino Unido.

Douglas, M. (1979) The world of goods: Towards an anthropology of consumption. Basic, New York.

Fang, T. (2003). A critique of Hofstede's fifth national culture dimension. International journal of cross cultural management, 3(3), 347-368. DOI:

https://doi.org/10.1177/1470595803003003006

Fearing, F. (1953) Towards a psychological of human communication. Journal of Personality, 22, 71-88. DOI: https://doi.org/10.1111/j.14676494.1953.tb01798.x 
Fellows, R. (2013) Use and misuse of the concept of culture. Construction Management and Economics, 31(5), 401-422. DOI: https://doi.org/10.1080/01446193.2013.794296

Gaskell, G. (2002). Entrevistas individuais $e$ grupais: Pesquisa qualitativa com texto, imagem e som: um manual prático. Vozes, Petrópolis.

Giarola, R. (2012) O povo novo brasileiro: mestiçagem e identidade no pensamento de Darcy Ribeiro. Tempo e Argumento, 4(1), 127140. DOI: https://doi.org/10.5965/2175180304012012127

Giron, L., Herédia, V. (2007) História da imigração italiana no Rio Grande do Sul. Edições EST, Porto Alegre.

Hall, E., Hall, M. (1990) Understanding cultural differences. Cultural Press, Yarmouth.

Harkness, J., Vijver, F., \& Mohler, P. (2003) Crosscultural survey methods. Wiley-Interscience, Hoboken.

Hassan, S. (2000) Determinants of market competitiveness in an environmentally sustainable tourism industry. Journal of Travel Research 38: 239-245. DOI: https://doi.org/10.1177/004728750003800305

Hofstede, G. (1980) Culture's consequences: international differences in work related values. Sage Publications, Thousand Oaks.

Hofstede, G. (2001) Culture's consequences: international differences in work related values. 2ed. Sage Publications, Thousand Oaks.

Holanda, B. (1973) Raízes do Brasil. José Olympio, Rio de janeiro.

House, R., Hanges, P., Javidan, M., Dorfman, P., Gupta, V. (2004) Culture, Leadership and Organizations. The Globe Study of 62 Societies. Sage Publications, Thousand Oaks.

Husted, B. (2005) Culture and ecology: A crossnational study of determinants of environmental sustainability. Management International Review, 45, 341-379.

Laraia, R, B. (2001) Cultura: um conceito antropológico. Zahar, Rio de Janeiro.

Kastenholz, E. (2010) Cultural proximity as a determinant of destination image. Journal of Vacation Marketing, 16(4), 313-322. DOI: https://doi.org/10.1177/1356766710380883

Kavaratzis, M. (2005). Place branding: A review of trends and conceptual models. The marketing review, 5(4), 329-342. DOi: https://doi.org/10.1362/146934705775186854

Kluckhohn, C. (1951) The study of culture. The policy sciences, 81-101.

Kotler, P., \& Gertner, D. (2002) Country as brand, product, and beyond: A place marketing and brand management perspective. Journal of brand management, 9(4), 249-261. DOI: https://doi.org/10.1057/palgrave.bm.2540076

Kroeber, A. L., Kluckhohn, C. (1952) Culture: $a$ critical review of concepts and definitions. Harvard University, Cambridge.

Maia, A. (2015) Diversidade cultural, identidade nacional brasileira e patriotismo constitucional. Fundação Casa de Rui Barbosa, Rio de Janeiro.

Mariutti, F. G., \& Medeiros, M. (2018). Culture as a dimension of country brand: highs and lows of Brazil's brand image. Tourism \& Management Studies, 14(1), 117-127. DOi: https://doi.org/10.18089/tms.2018.14110

McCracken, G. (1986). Culture and consumption: A theoretical account of the structure and movement of the cultural meaning of consumer goods. Journal of consumer research, 13(1). 7184. DOI: https://doi.org/10.1086/209048

Miglievich, M. (2011) A crítica pós-colonial a partir de Darcy Ribeiro: uma releitura de o povo brasileiro. Revista de Estudos Antiutilitaristas e Pós-Coloniais, 1(1), 134-146.

Money, R. B., Crotts, J. C. (2003). The effect of uncertainty avoidance on information search, 
planning, and purchases of international travel vacations. Tourism Management, 24(2), 191-202. DOI: https://doi.org/10.1016/S0261-5177(02)00057$\underline{2}$

Mooij, M. (2014) Global marketing and advertising: understanding cultural paradoxes. Sage Publications, Thousand Oaks.

Neto, H. Bezzi, M. (2007) Regiões culturais: a construção de identidades culturais no Rio Grande do Sul e sua manifestação na paisagem gaúcha. Revista Sociedade \& Natureza, 20(2): 135-155. DOI: https://doi.org/10.1590/S1982$\underline{45132008000200009}$

Ortiz, R. (2005) Cultura brasileira e identidade nacional. Editora Brasiliense, Rio de Janeiro.

Park, C., Jaworski, B., Macinnis, D. (1986) Strategic brand concept-image management. The Journal of Marketing, 50(4), 135-145. DOI: https://doi.org/10.1177/002224298605000401

Player. (2018) Cambridge Dictionary Online. Cambridge: Cambridge University Press, Inc. Retrieved July 20, 2018, from https://dictionary.cambridge.org/dictionary/english/ player.

Poynter, R. (2010) The handbook of online and social media research: Tools and techniques for market researchers. John Wiley\& Sons.

Ribeiro, D. (1995) O Povo Brasileiro: a formação e o sentido do Brasil. Companhia das Letras, São Paulo.

Roth, M. (1995) The effects of culture and socioeconomics on the performance of global brand image strategies. Journal of Marketing Research, 32(2), 163-175. DOI: https://doi.org/10.2307/3152045

Roy, A., Goll, I. (2014) Predictors of various facets of sustainability of nations: The role of cultural and economic factors. International Business Review, 23, 849-861. DOI: https://doi.org/10.1016/j.ibusrev.2014.01.003
Sahlins, M. (2013). Culture and practical reason. University of Chicago Press, Chicago, Estados Unidos.

Schein, E. H. (2010) Organizational culture and leadership. John Wiley \& Sons, San Francisco.

Schultz, P., Gouveia, V., Cameron, L., Tankha, G., Schmuck, P., Franek, M. (2005) Values and their relationship to environmental concern and conservation behavior. Journal of cross-cultural psychology, 36(4), 457-475. DOI: https://doi.org/10.1177/0022022105275962

Smith, S. L. (2010). Practical tourism research. Boston, Cabi. DOI: https://doi.org/10.1079/9781845936327.0000

Souza, A., Farias, S., Brito, M.(2014) Cultural dimensions and image: an essay on the impacts of masculinity and individualism on the interpretation of the sustainability of tourism destinations. Revista Brasileira de Pesquisa em Turismo, 8(2), 238-260. DOI: https://doi.org/10.7784/rbtur.v8i2.723

Stern, B., Zinkhan, G. M., \& Jaju, A. (2001). Marketing images: Construct definition, measurement issues, and theory development. Marketing Theory, 1(2), 201-224. DOI: https://doi.org/10.1177/147059310100100203

Stewart, K., \& Williams, M. (2005). Researching online populations: the use of online focus groups for social research. Qualitative Research, 5(4), 395-416. DOI: https://doi.org/10.1177/1468794105056916

Stewart, D. W., \& Shamdasani, P. N. (2014). Focus groups: Theory and practice. v. 2. Sage publications, Thousand Oaks.

Tabellini, G. (2010) Culture and institutions: economic development in the regions of Europe. Journal of the European Economic Association, 8(4), 677-716. DOI: https://doi.org/10.1111/i.15424774.2010.tb00537.x

Trombini, J. (2017) Imigrantes italianos e seus descendentes na microrregião oeste do Vale do 
Taquari: história ambiental e práticas culturais. (Master's thesis).

Turner, R. K., Pearce, D., \& Bateman, I. (1994) Environmental economics: an elementary introduction. Baltimore, Harvester Wheatsheaf.

Valsiner, J. (2007) Culture in minds and societies: Foundations of cultural psychology. Psychological Studies, 54, 238-239.

Warren, G., \& Dinnie, K. (2018) Cultural intermediaries in place branding: Who are they and how do they construct legitimacy for their work and for themselves? Tourism Management, 66, 302-314. DOI: https://doi.org/10.1016/i.tourman.2017.12.012

Zouganeli, S., Trihas, N., Antonaki, M., Kladou, S. (2012) Aspects of sustainability in the destination branding process: a bottom-up approach. Journal of Hospitality Marketing \& Management, 21, 739-757. DOI: https://doi.org/10.1080/19368623.2012.624299

Informações dos autores

Adrielly Souza Silva

Estudante de Mestrado em Hotelaria e Turismo no
PPHTUR/DHT - Universidade Federal de Pernambuco (UFPE). Possui graduação no curso de Bacharelado em Turismo pela UFPE.

E-mail: dellysouzas@gmail.com

ORCID: https://orcid.org/0000-0002-8259-8602

\section{Anderson Gomes de Souza}

Doutor e Mestre em Administração pelo Programa de Pós-Graduação em Administração - PROPAD/UFPE, especialista em Marketing, Advertising and International Business Communications (MLS International College - UK), possui graduação em Turismo pela Universidade Federal de Pernambuco (UFPE). Atualmente é Professor Adjunto II do Departamento de Hotelaria e Turismo - DHT/UFPE, atuando nos cursos de Bacharelado em Turismo e Bacharelado em Hotelaria, bem como no Programa de Pós-Graduação em Hotelaria e Turismo - PPHTUR/UFPE. Membro da Academia Internacional para o Desenvolvimento da Pesquisa em Turismo no Brasil (ABRATUR). Integrante do Centro de Estudos em Hospitalidade, Turismo e Gastronomia CHT/UFPE; do ConsuMeering - Engenharia do Consumidor (UFPE) e do eCOS/UFPE. Atua principalmente nos seguintes temas: marketing e comunicação publicitária em turismo; risco percebido e experiência de consumo no setor de serviços, com ênfase em hospitalidade; comportamento do consumidor aplicado a segmentos específicos de mercado; estudos cross-culturais e consumo.

E-mail: son_ander@hotmail.com

ORCID: https://orcid.org/0000-0002-5370-7726 